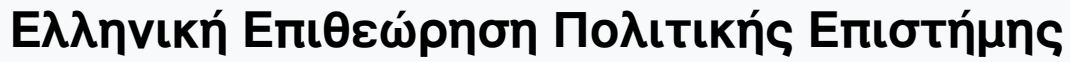

Tó 40 (2013)

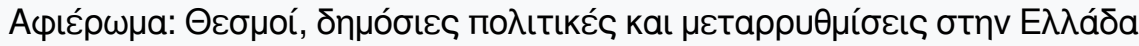

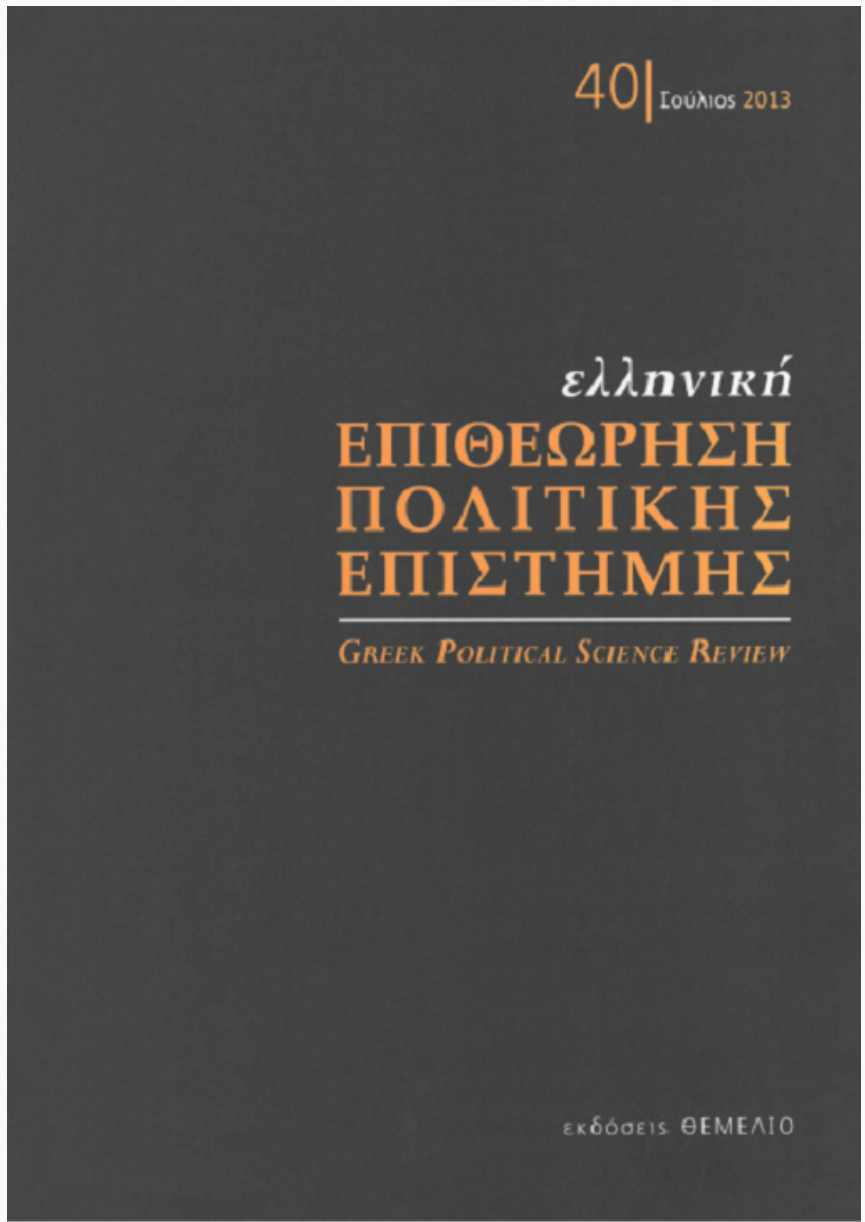

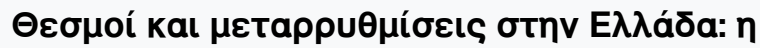

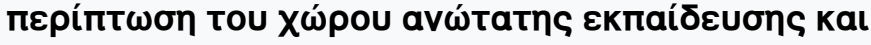

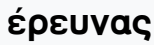

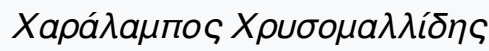

doi: $10.12681 / \mathrm{hpsa} .14558$

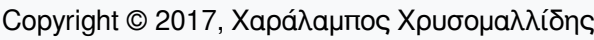

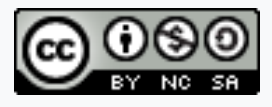

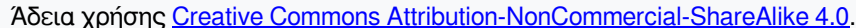

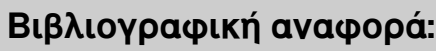

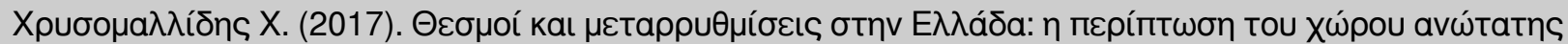

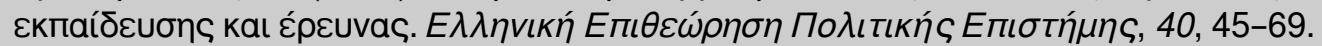

https://doi.org/10.12681/hpsa.14558 


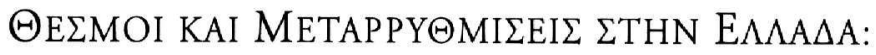 \\ H ПЕРIПТ $\Omega$ $\Sigma$ TOY X $\Omega$ POY

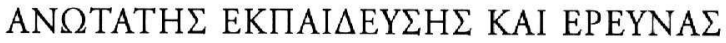

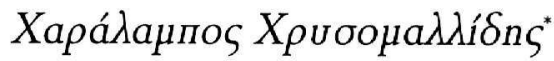

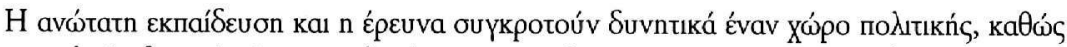

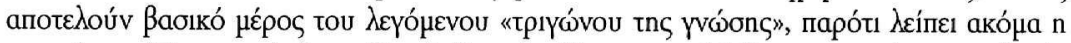

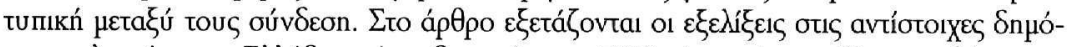

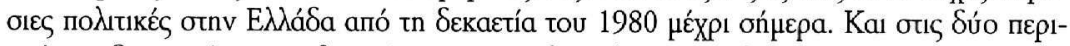

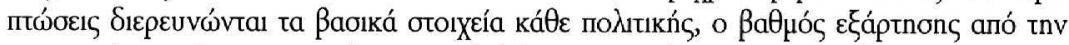

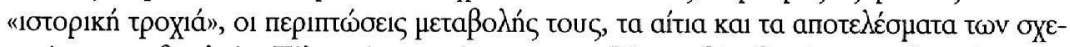

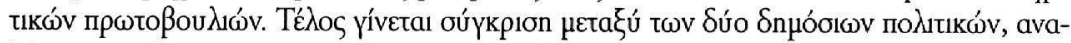

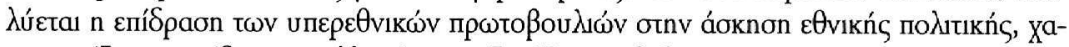

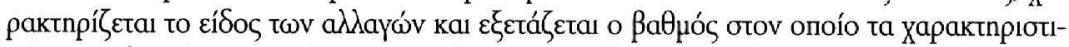

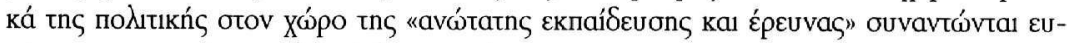

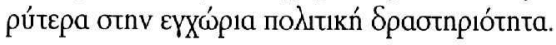

\section{1. $\mathrm{EI} \Sigma \mathrm{A} \Omega \Omega \Gamma \mathrm{H}$}

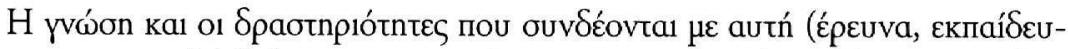

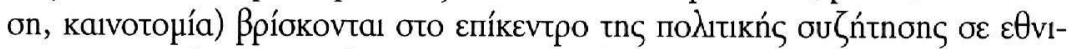

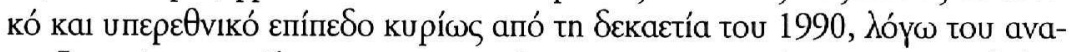

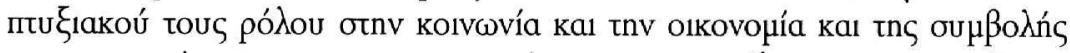

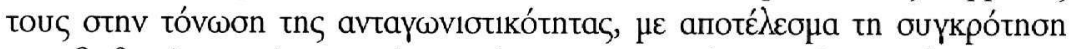

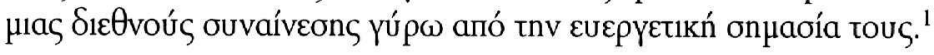

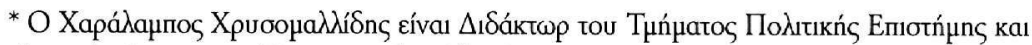

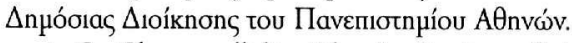

1. C. Chrysomallidis, The Application of the Knowledge-Based Model of Growth in Greece. The Case of Inefficient National Research Policy, LAP Lambert Academic Publishing, Saarbruecken 2010, o. 11. 


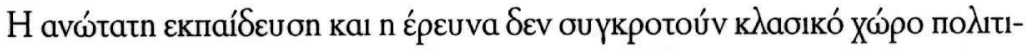

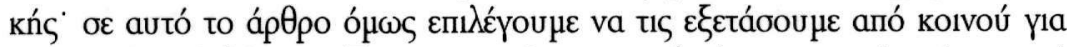

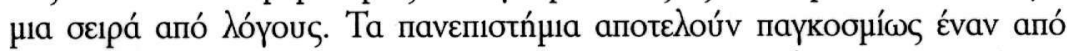

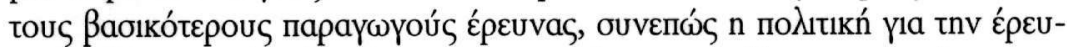

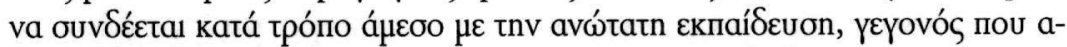

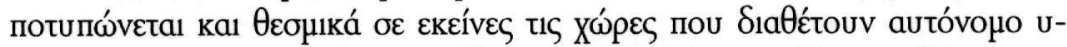

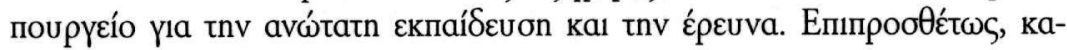

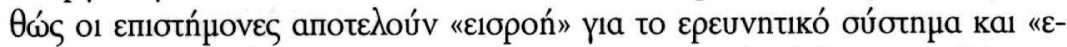

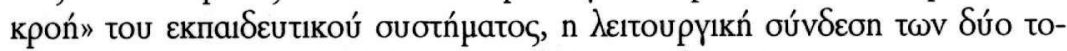

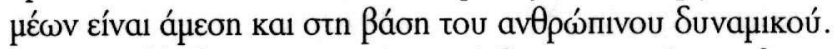

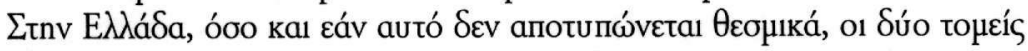

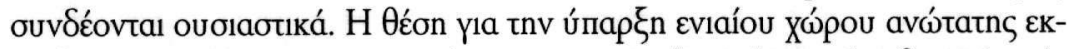

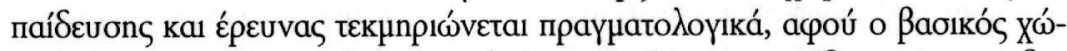

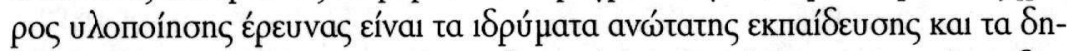

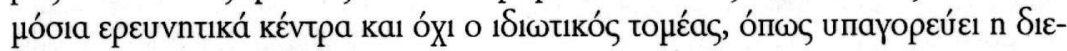

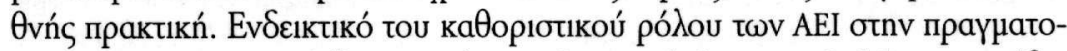

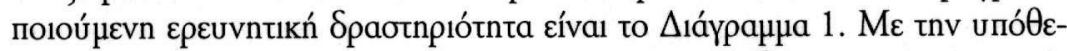

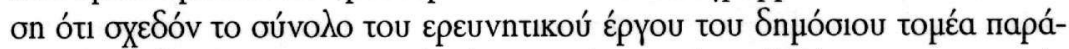

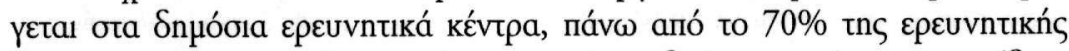

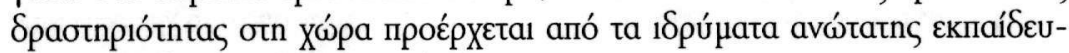

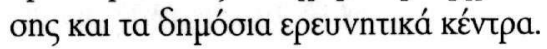

\section{$\triangle$ IAГPAMMA 1}

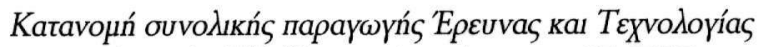

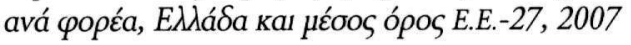

Eגsáóa

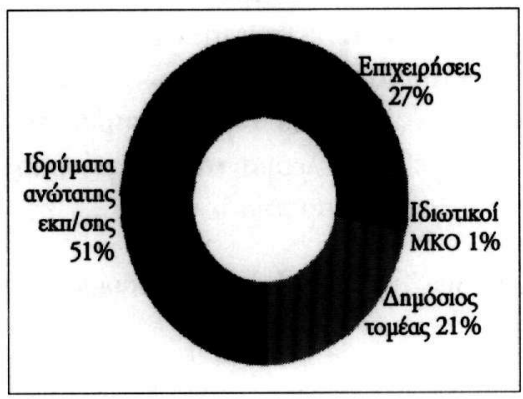

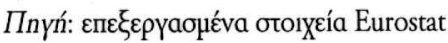

E.E. -27

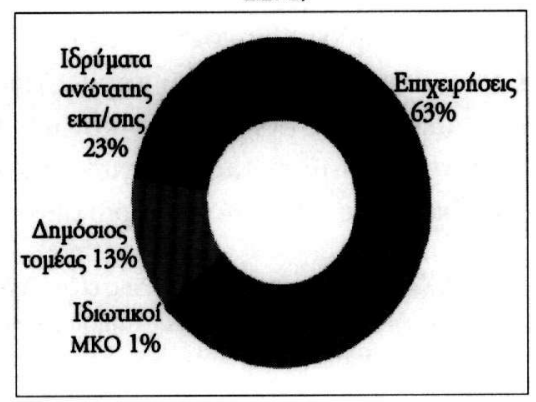




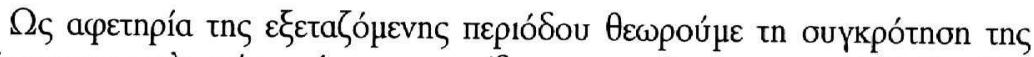

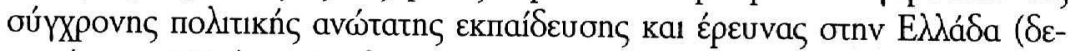

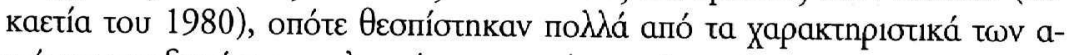

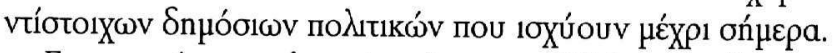

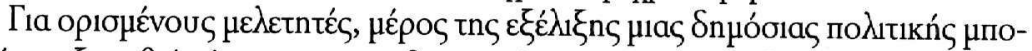

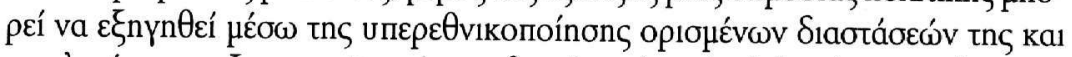

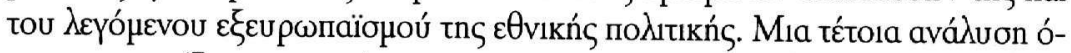

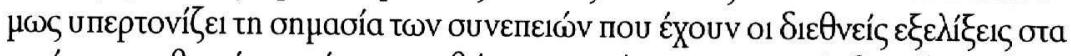

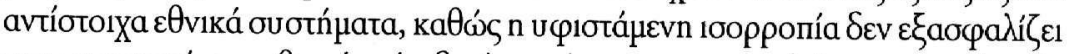

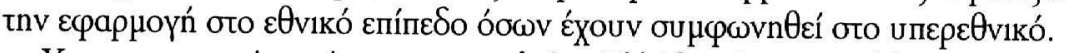

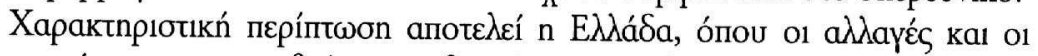

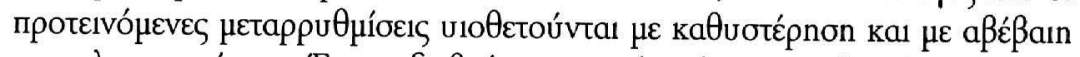

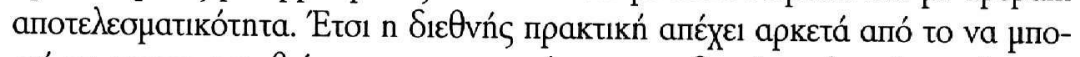

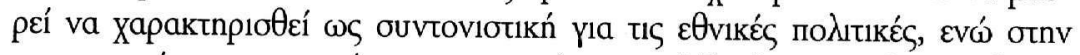

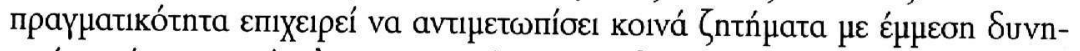

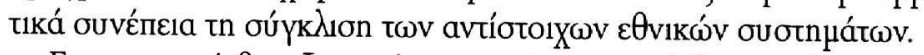

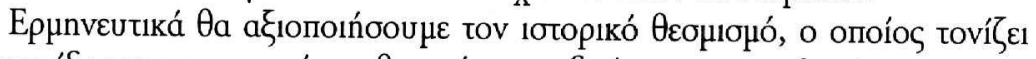

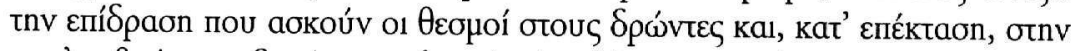

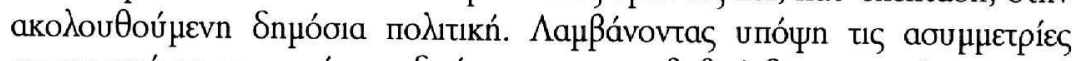

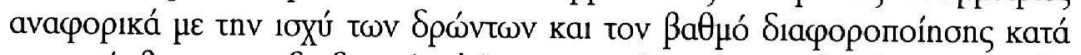

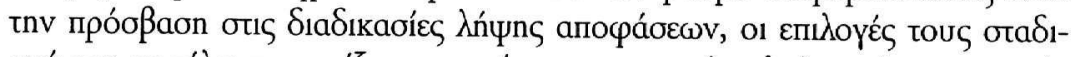

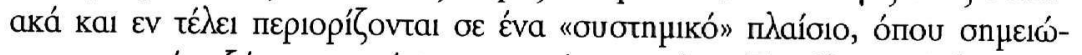

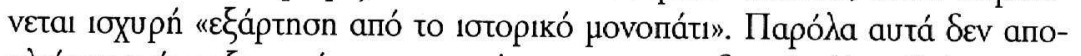

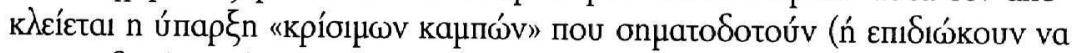

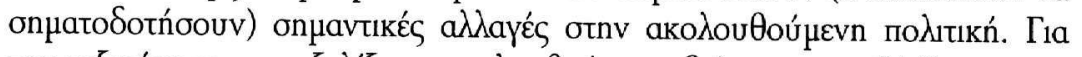

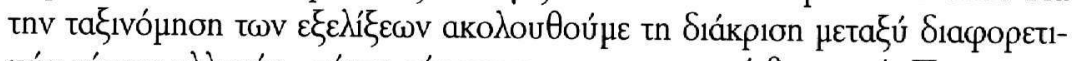

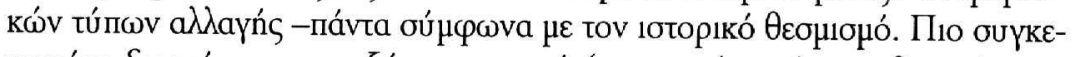

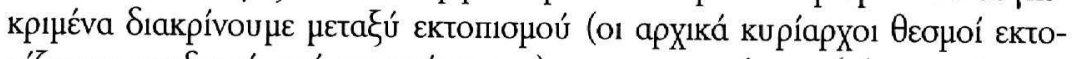

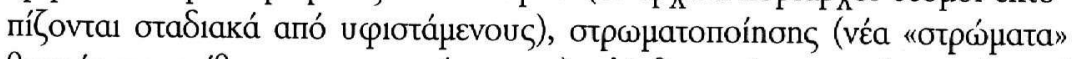

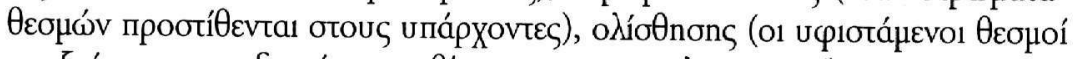

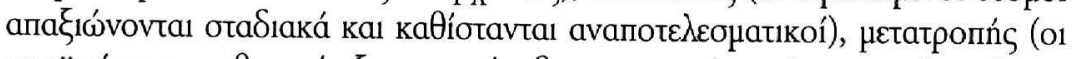

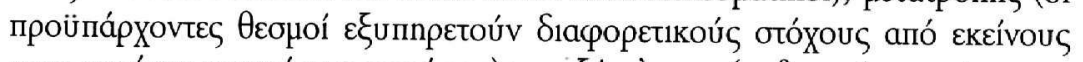

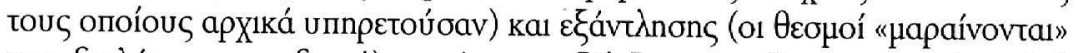

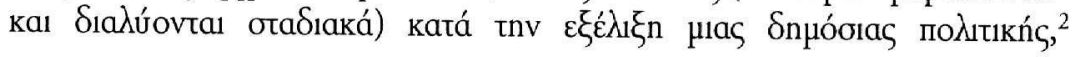

2. W. Streeck - K. Thelen, «Introduction: institutional change in advanced political

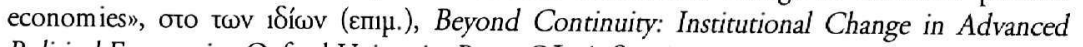

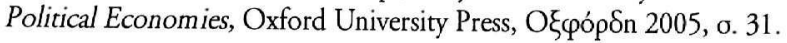




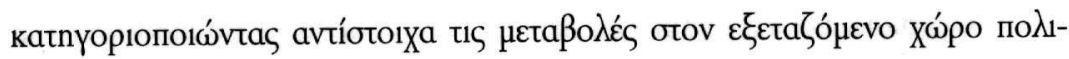
tıkńc.

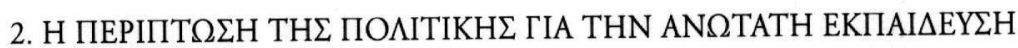 $\Sigma T H N$ E $\Lambda \Lambda A \triangle A$}

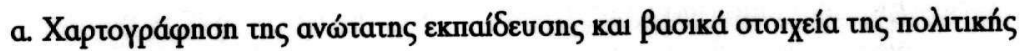

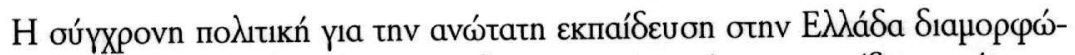

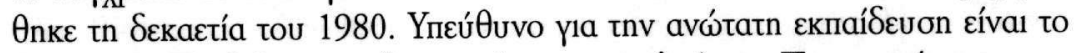
Yпоu

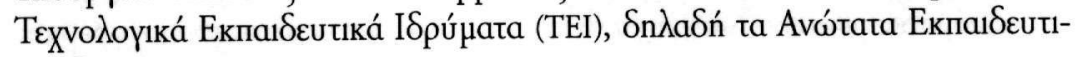

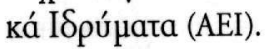

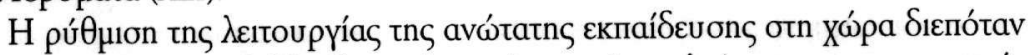

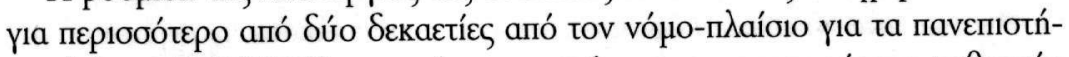

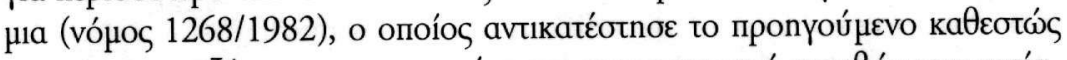

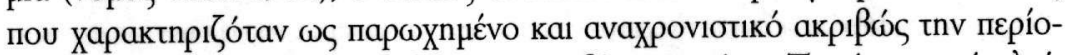

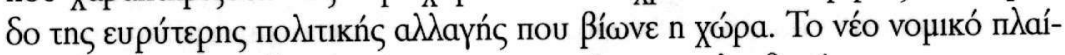

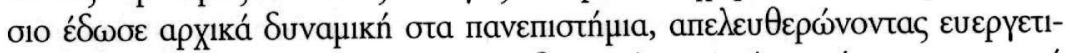

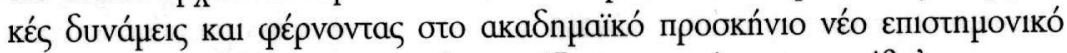

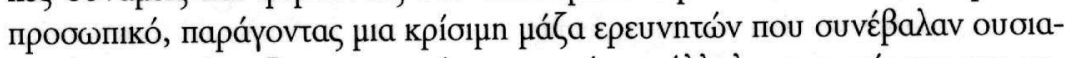

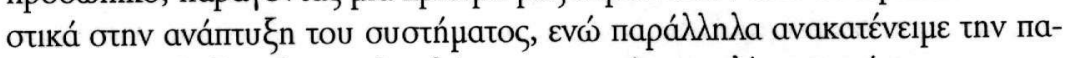

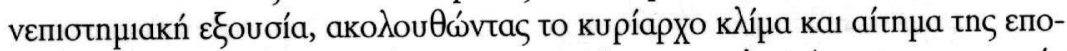

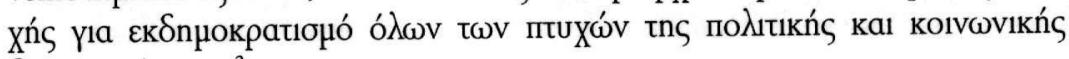
¿paotnpiótntas. ${ }^{3}$

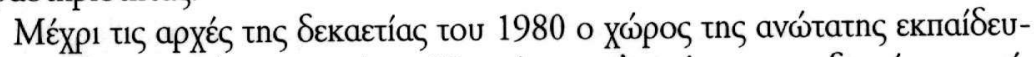

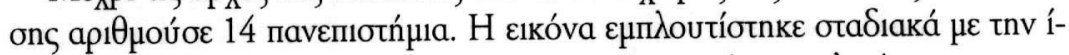

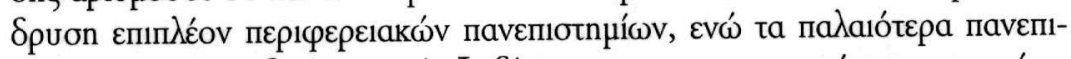

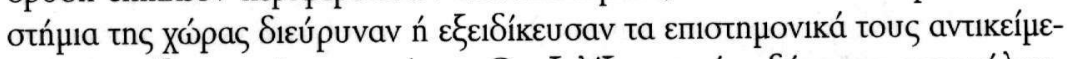

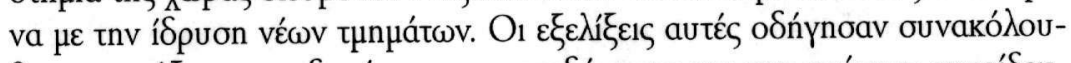

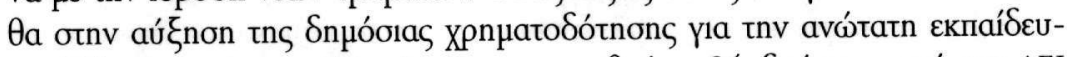

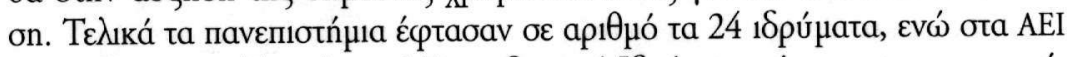

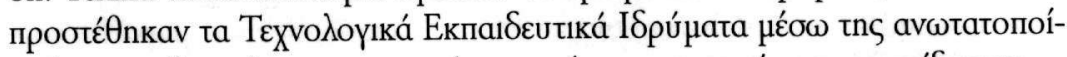

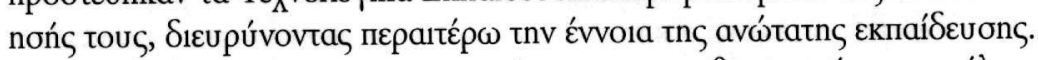

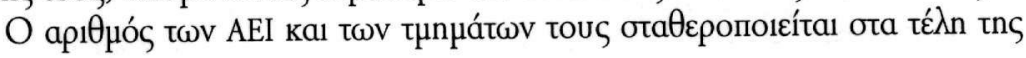

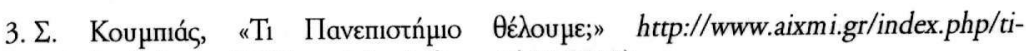
panepistimio-theloume/ 2011, о. 1 (про́оßaon 14.11.2012). 


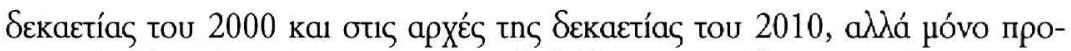

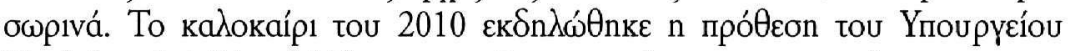

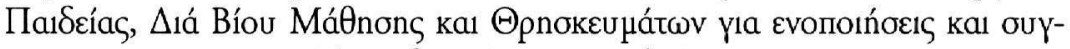

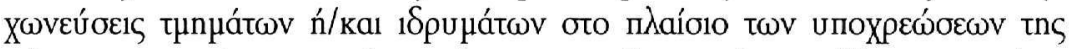

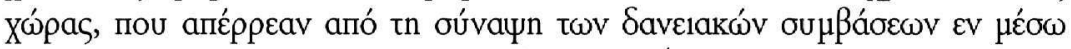

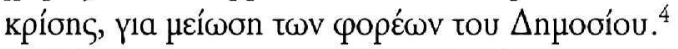

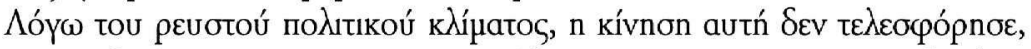

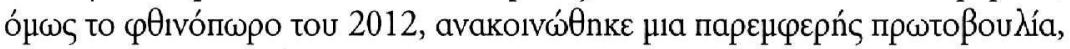
to "OXर́์

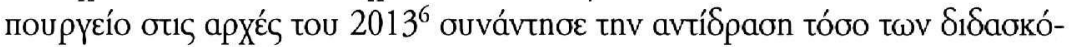

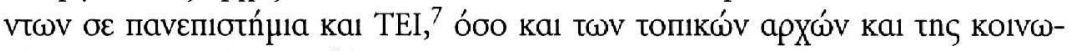

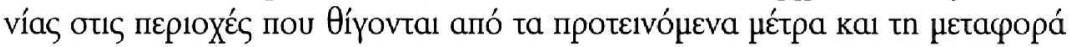

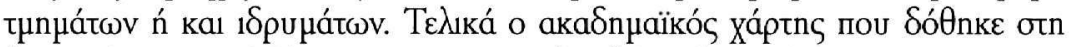

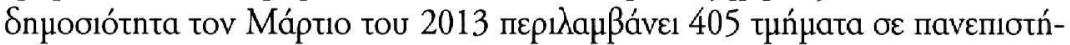

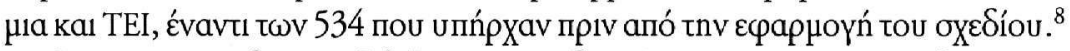

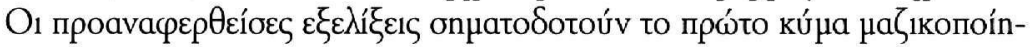

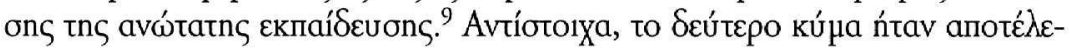

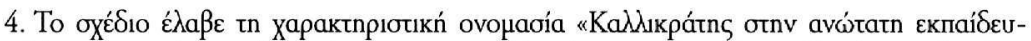

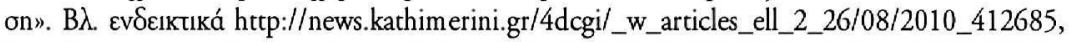
http://www.enet.gr/?i=issue.el.home\&date=14/11/2010\&id $=223609$ (nрóøßaon 15.12.2012).

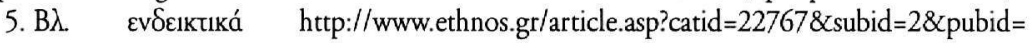
63690987, http://www.tovima.gr/society/article/?aid=487946 (npóoßaon 15.12.2012).

6. http://www.minedu.gov.gr/publications/docs2013/130131_sxedio_athhna_deltio_typoy. pdf (поóoßaon 31.01.2013).

7. http://www.alfavita.gr/arthra/\%CE $\%$ BF \%CF $\% 83 \%$ CE $\%$ B $5 \%$ CF $\% 80-\%$ CF\%84\%CE\%B5\%CE\%B9-\%CF\%83\%CF\%87\%CE\%B5\%CF\%84\%CE\%B9\%CE\% BA\%CE\%AC- $\%$ CE $\%$ BC $\%$ CE $\%$ B $5-\%$ CF\% $84 \%$ CE $\%$ BF\%CF\%83\%CF $\% 87 \%$ CE $\%$ AD $\%$ CE\%B4\%CE\%B9\%CE\%BF-\%CE\%B1\%CE\%B8\%CE\%B7\%CE\%BD\%CE\%AC ка http://www.inews.gr/240/apopsi-tis-posdep-gia-to-schedio-athina.htm (npóoßaon 8.2.2013).

8. http://www.esos.gr/article/eidisis-tritovathmia-ekpaidefsi/teliko_sxedio_athina_ ta_405_tmimata, http://www.megatv.com/megagegonota/article.asp?catid $=27369 \&$ subid $=2 \&$ pubid $=30760475$ kal http://www.esos.gr/uploads/axiologisi/neos_akadhmaikos_xartis.pdf (nрóoßaơn 23.3.2013).

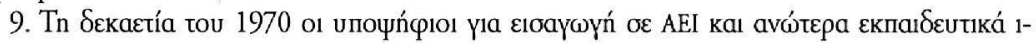

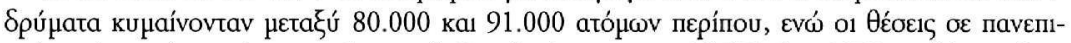

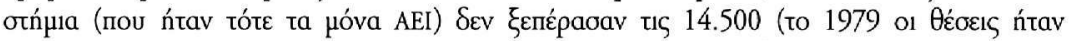

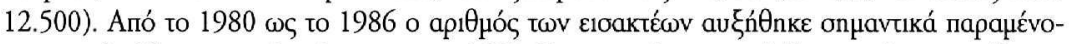

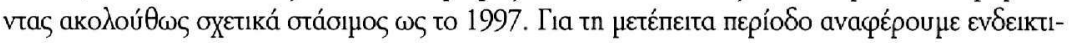

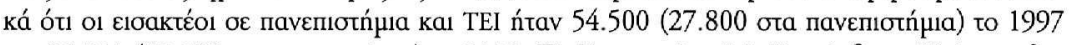

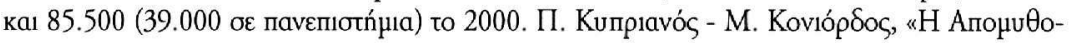




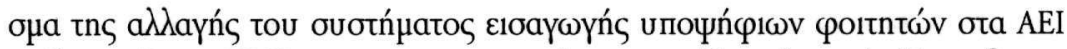

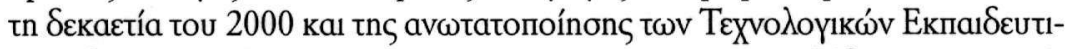

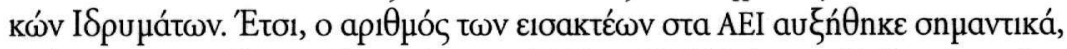

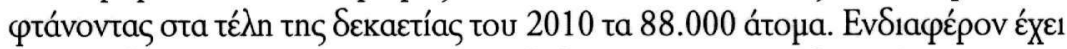

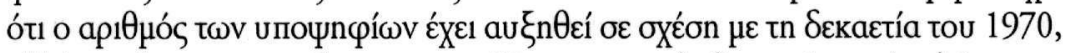

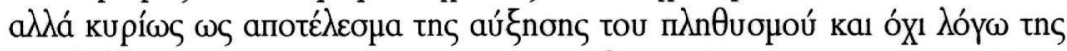

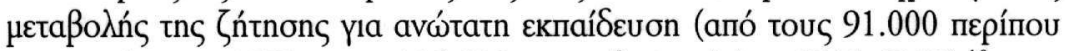

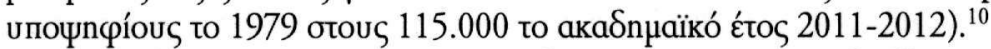

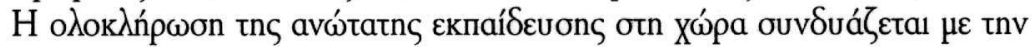

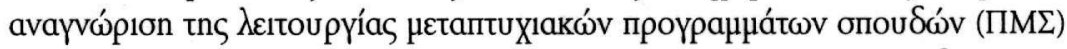

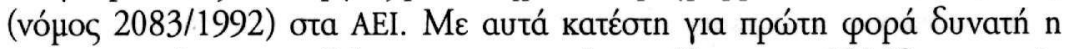

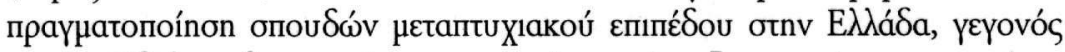

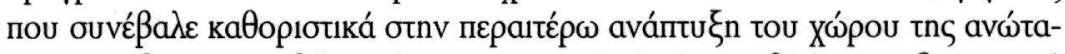

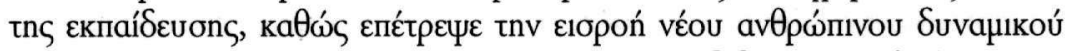

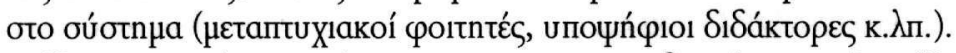

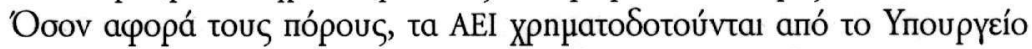

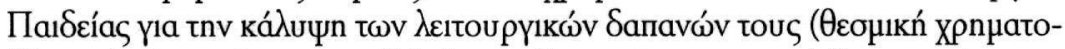

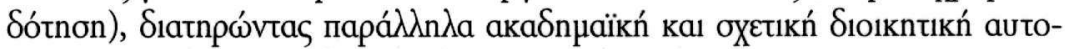

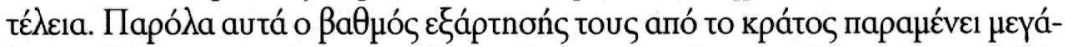

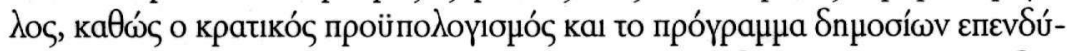

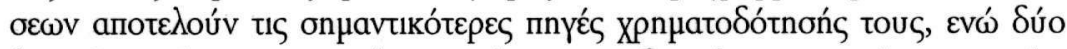

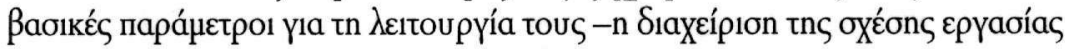

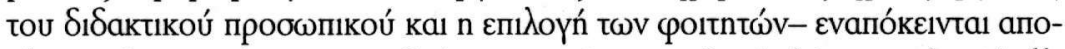

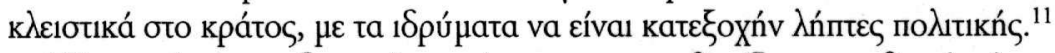

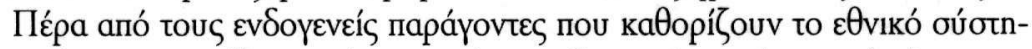

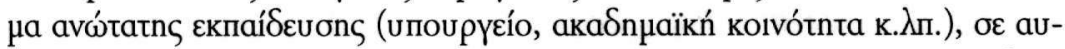

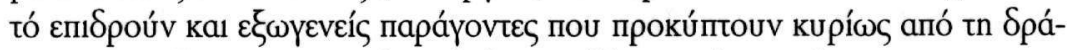

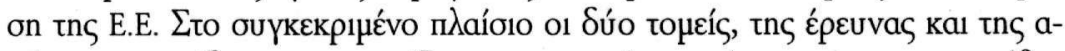

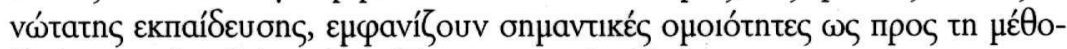

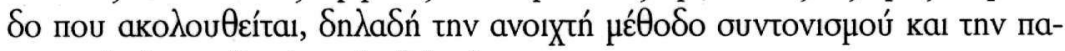

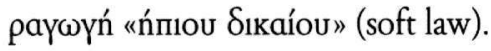

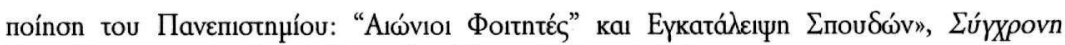

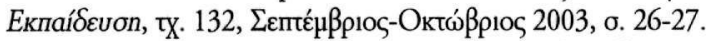

10. http://news.kathimerini.gr/4dcgi/_w_articles_ell_2_11/05/2011_441734 (прóoßaon 14.11.2012).

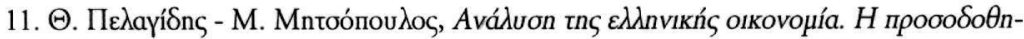

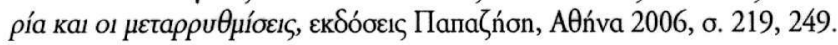




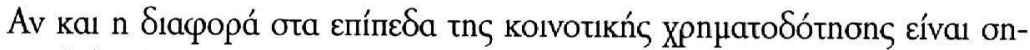

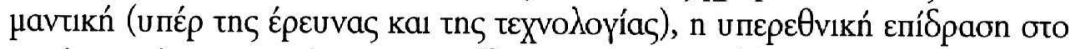

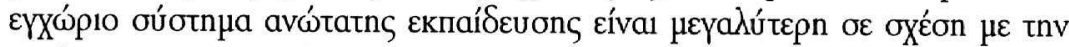

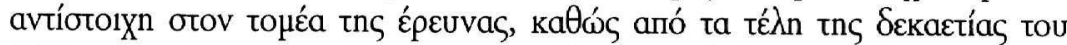

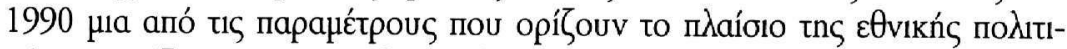

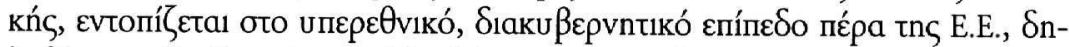

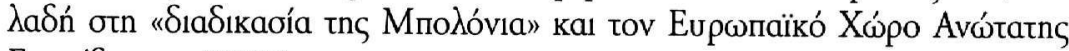
Eknaífeuons (EXAE).

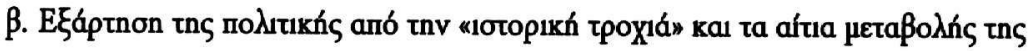

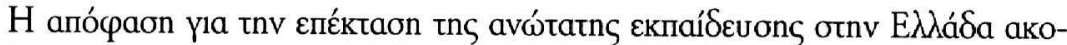

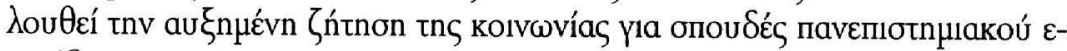

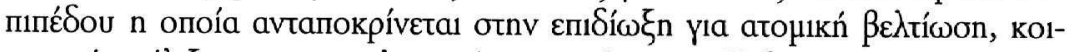

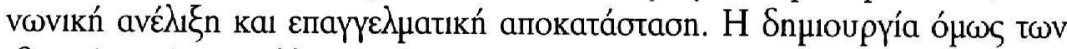

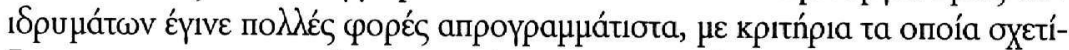

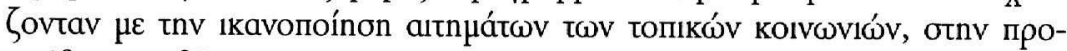

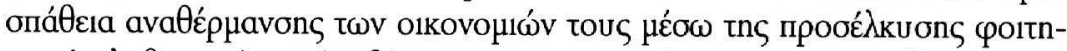

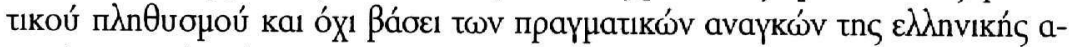

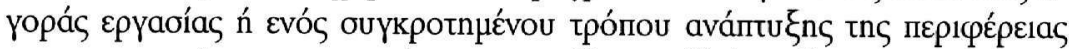

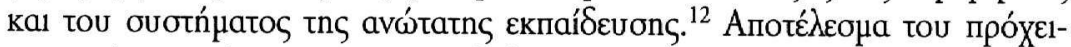

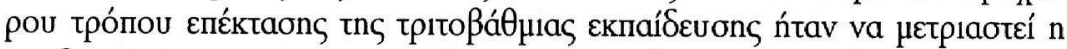

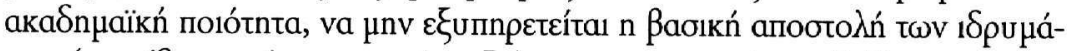

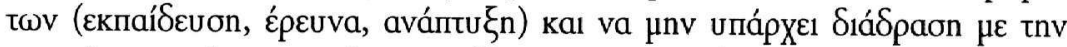

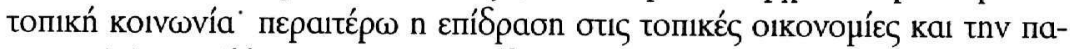

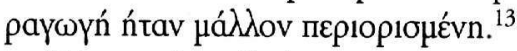

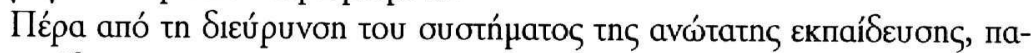

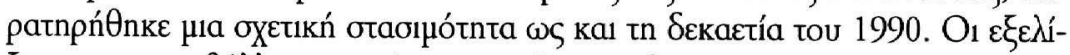

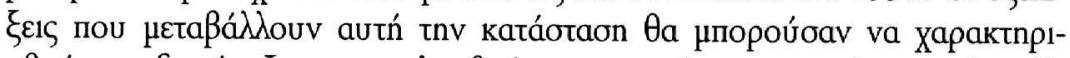

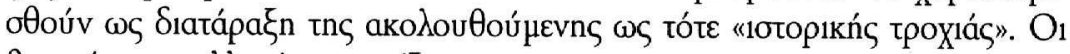

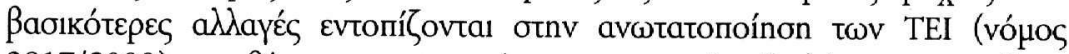

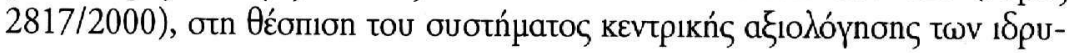

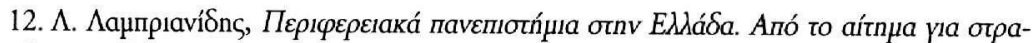

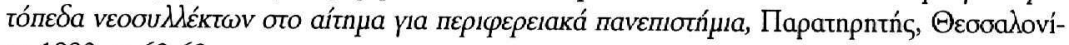
kn 1993, о. 62-63.

13. L. Labrianidis, "The Greek University Stranded in the Policy of Establishing Regional Universities», European Planning Studies, tóp. 18, тx. 12, 2010, б. 2009, 2012, 2022. 


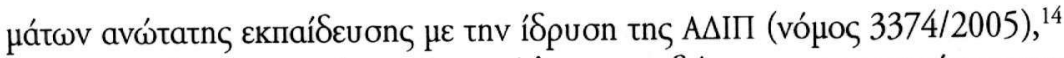

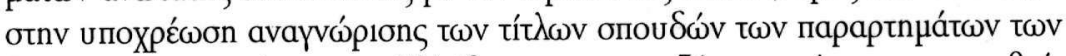

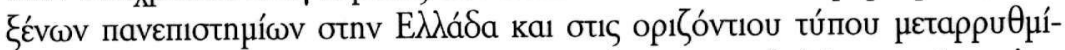

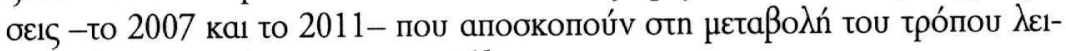

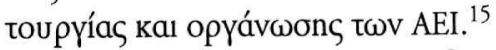

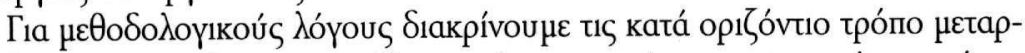

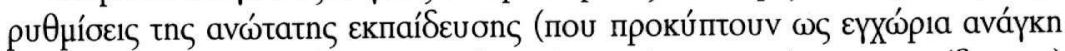

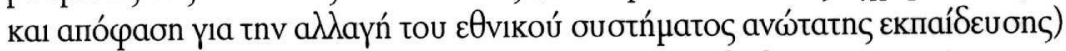

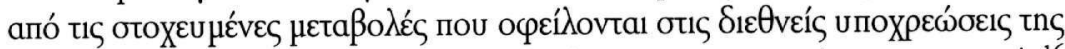

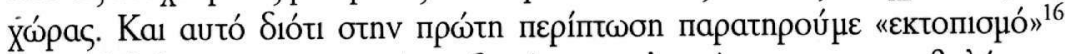

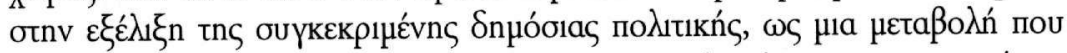

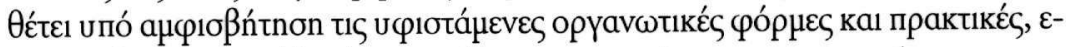

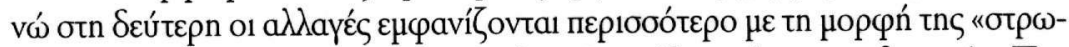

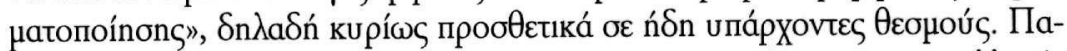

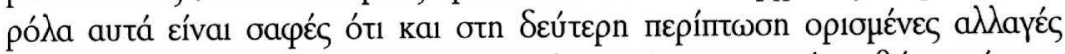

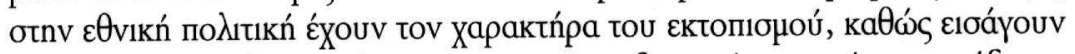

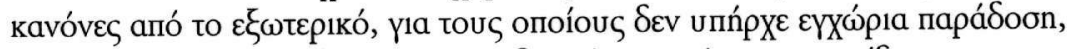

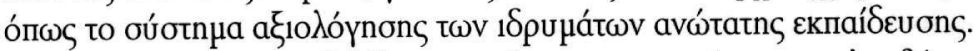

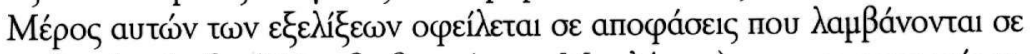

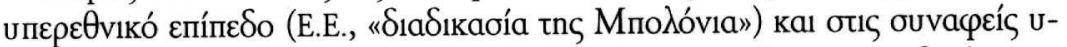

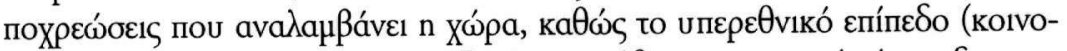

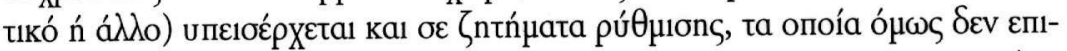

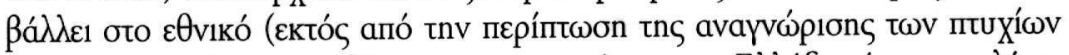

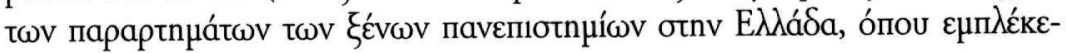

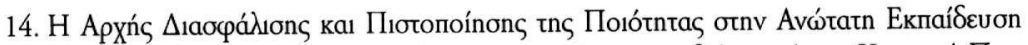

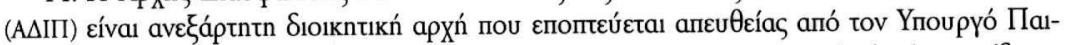

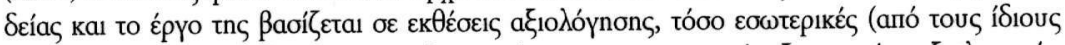

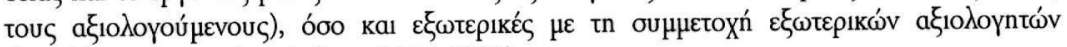
(http://www.hqaa.gr/, прóoßaon 14.11.2012).

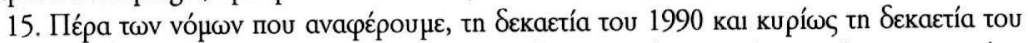
2000 чn

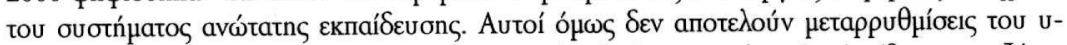

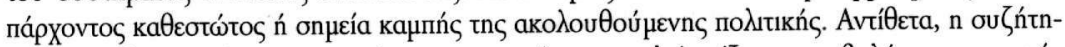

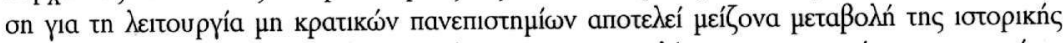

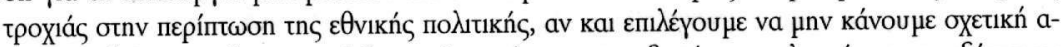

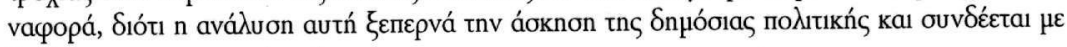

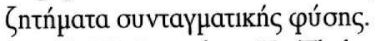

16. W. Streeck - K. Thelen, «Introduction: institutional change in advanced political economies», ó.n., б. 19. 


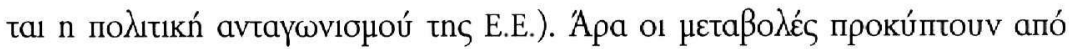

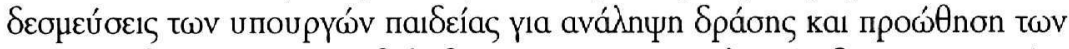

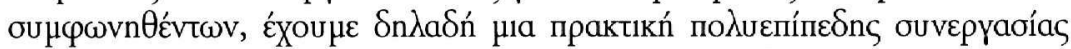

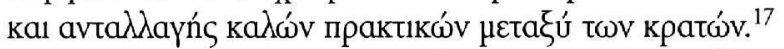

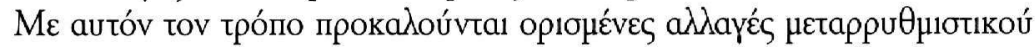

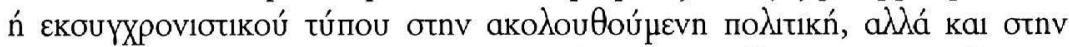

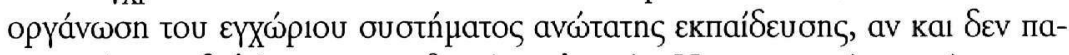

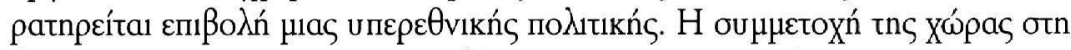

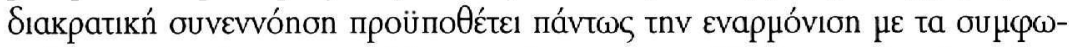

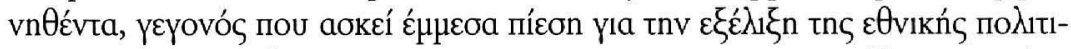

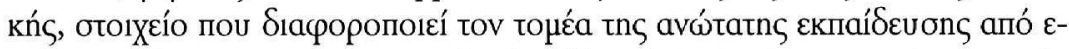

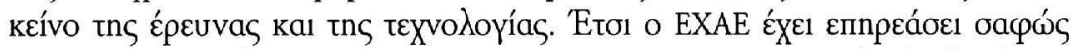

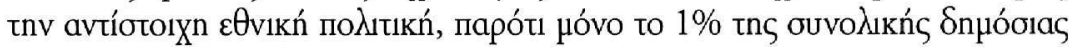

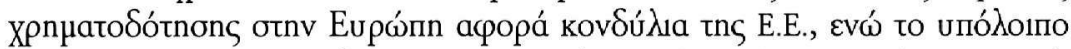

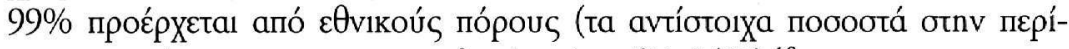

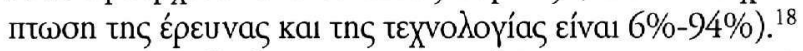

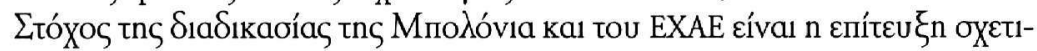

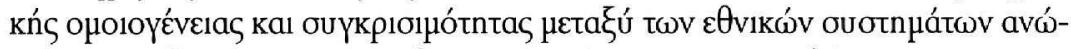

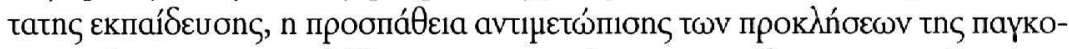

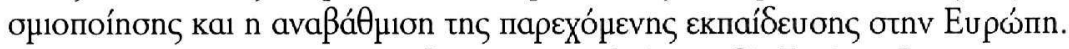

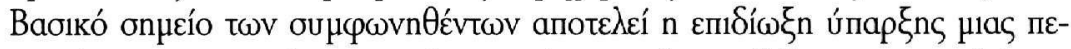

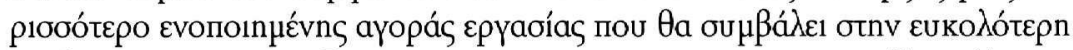

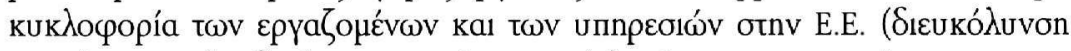

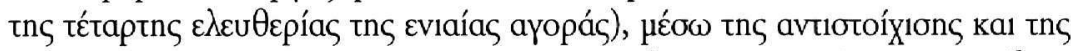

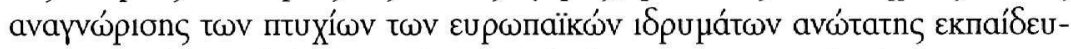

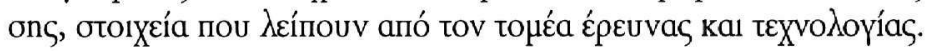

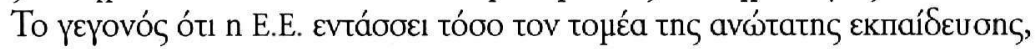

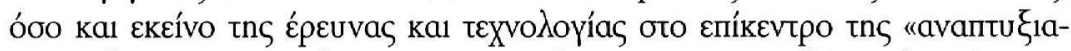

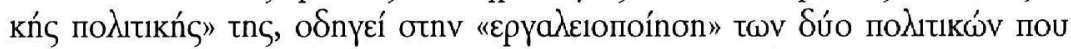

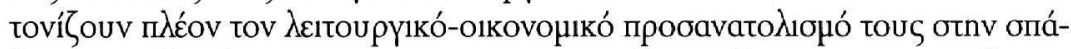

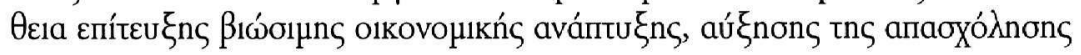

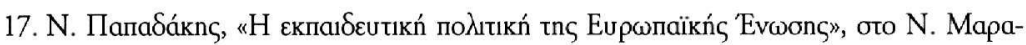

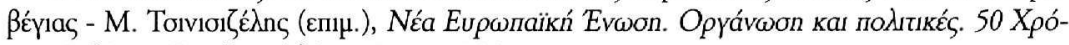

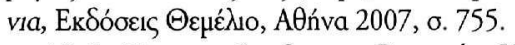

18. J. Ritzen - L. Soete, «Research, Higher Education and Innovation: Redesigning European Governance in a Period of Crisis", Notre Europe, Project How to spend better together, Policy Paper 49, 2011, o. 8. 


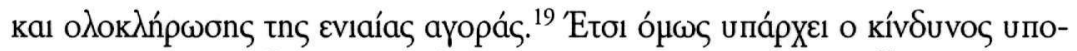

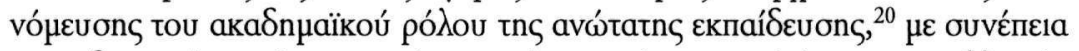

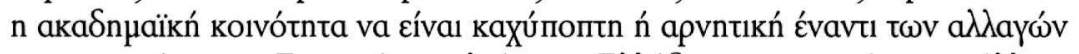

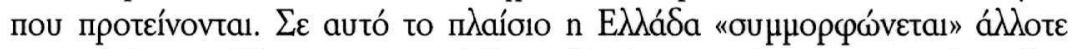

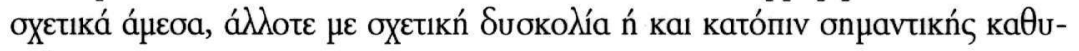
otépnons.

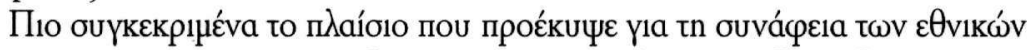

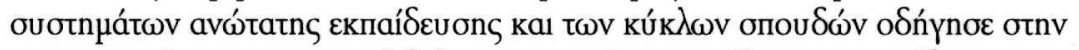

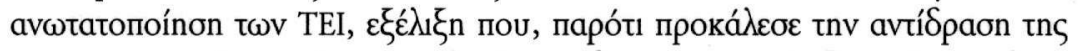

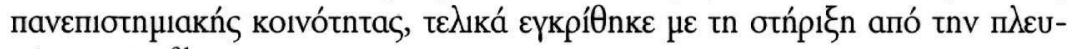
pá $\tau \omega \mathrm{v}$ TEI. ${ }^{21}$

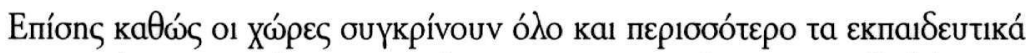

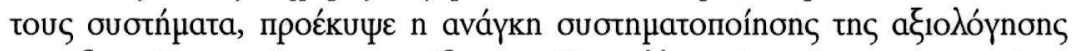

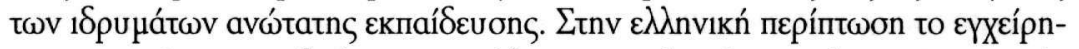

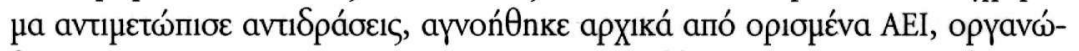

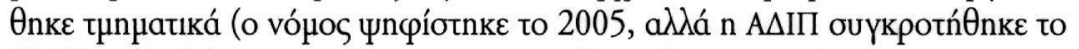

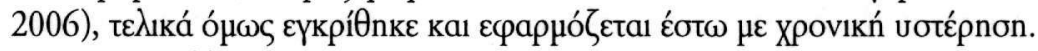

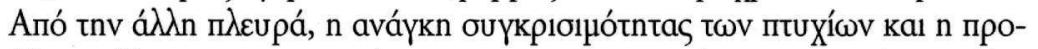

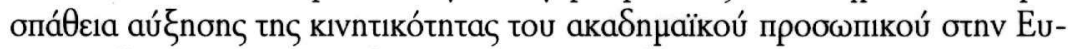

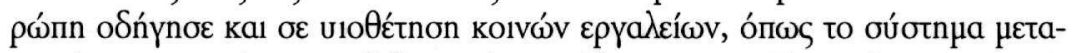

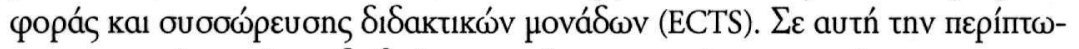

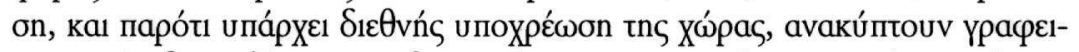

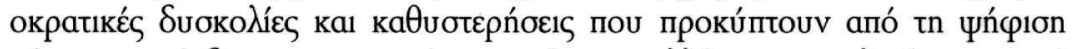

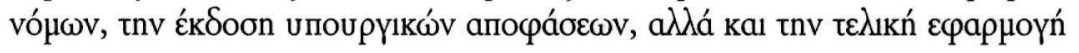

19. A. Gornitzka, "Coordinating Policies for a "Europe of Knowledge". Emerging Practices of the Open Method of Coordination in Education and Research", Arena Centre for European Studies, Working Paper ap. 16, Máptios 2005, o. 16-17. H. Walkenhorst, "Explaining Change in EU Education Policy», Journal of European Public Policy, tóp. 15, זx. 4, 2008, б. 569.

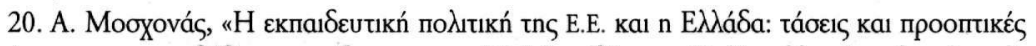

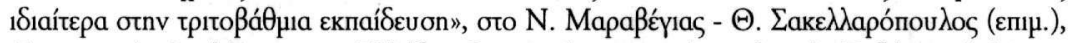

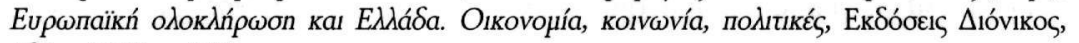
A日ńva 2006, б. 339.

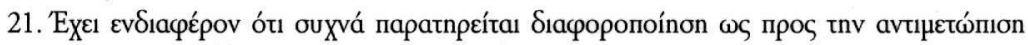

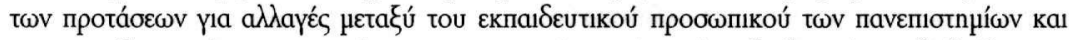

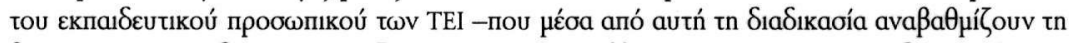

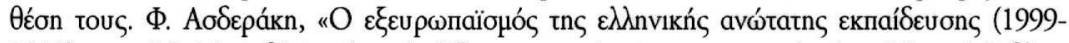

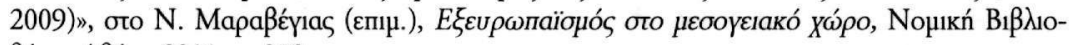
Өńkn, AӨńva 2011, o. 312. 


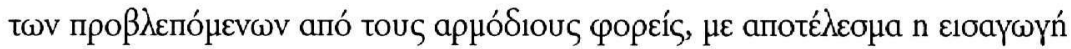

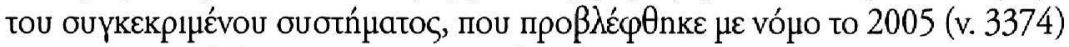

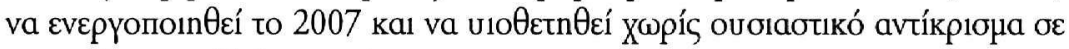

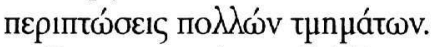

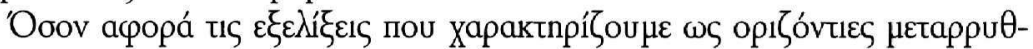

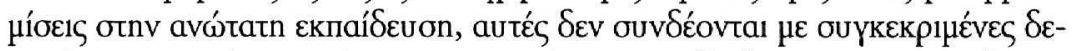

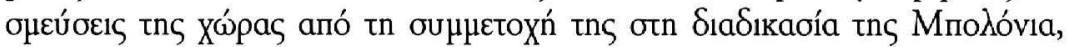

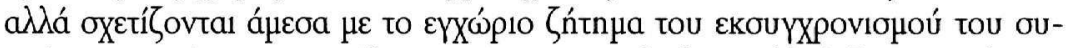

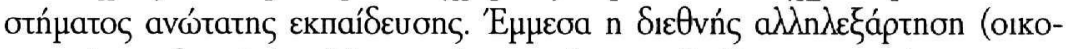

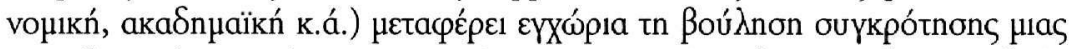

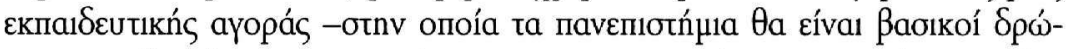

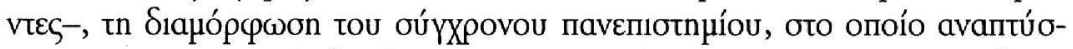

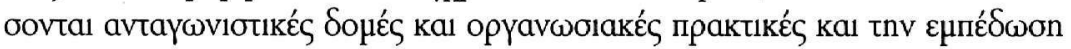

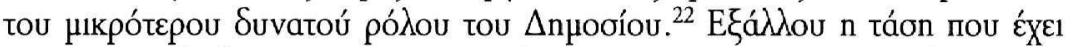

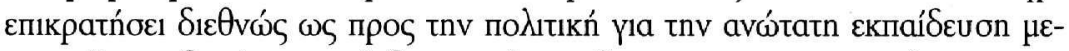

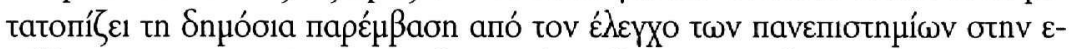

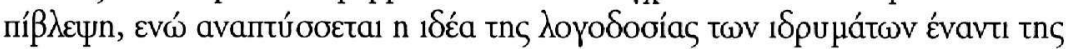

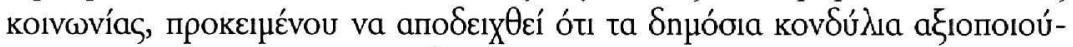

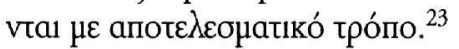

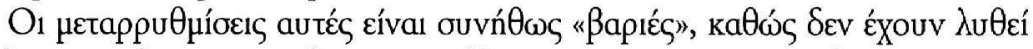

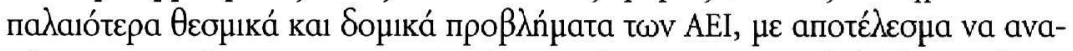

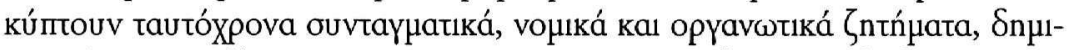

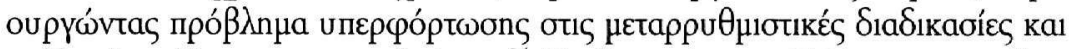

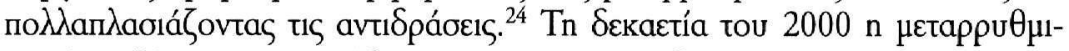

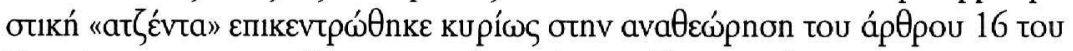

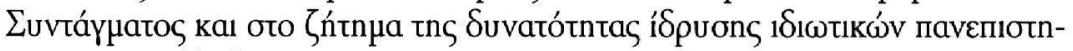

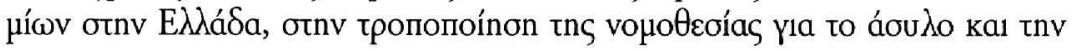

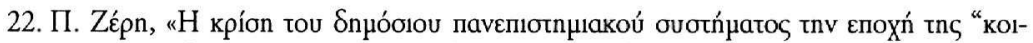

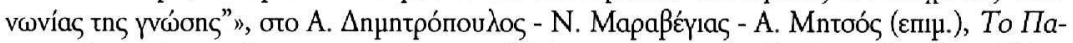

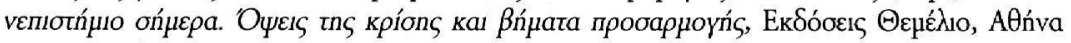
2010, o. 124-125.

23. A. Amaral, «Higher education in the process of European integration, globalizing economies and mobility of students and staff" ", oto J. Huisman - P. Maasen - G. Neave ( $\varepsilon$ mip.), Higher Education and the Nation State. The International Dimension of Higher

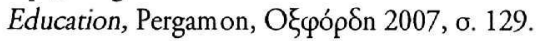

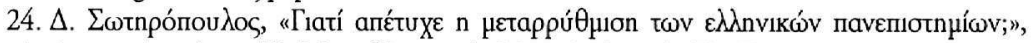

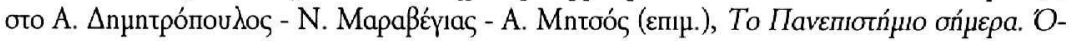

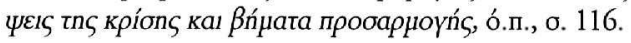




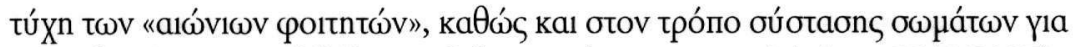

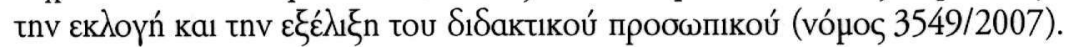

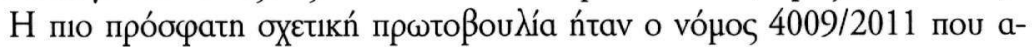

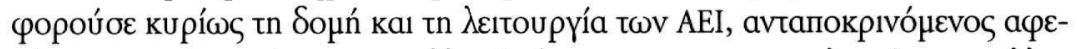

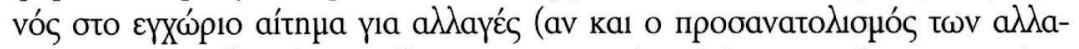

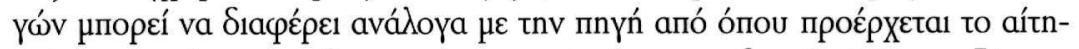

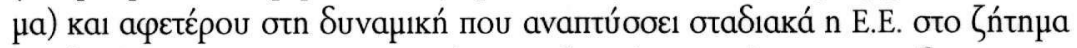

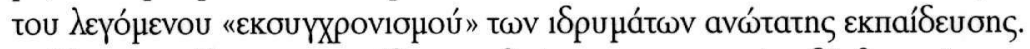

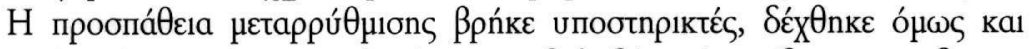

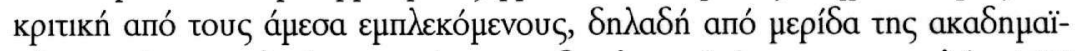

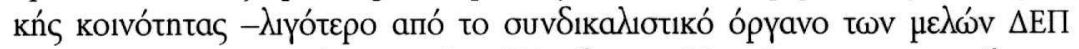

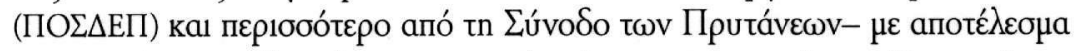

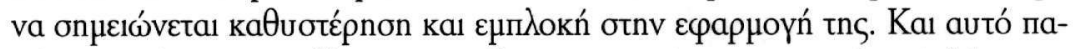

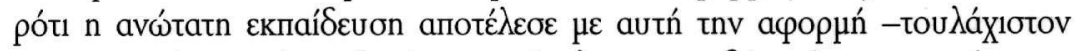

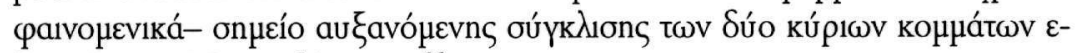

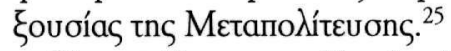

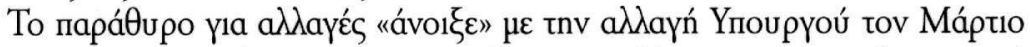

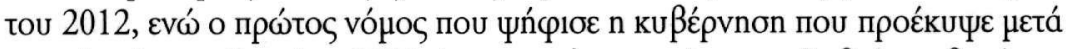

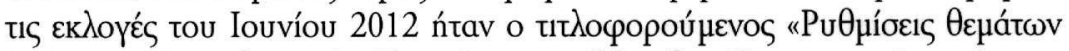

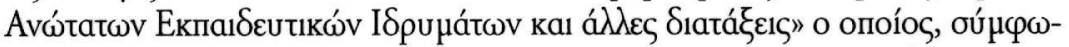

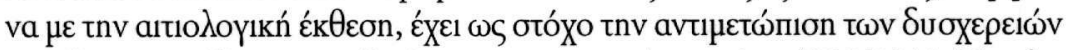

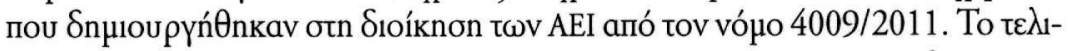

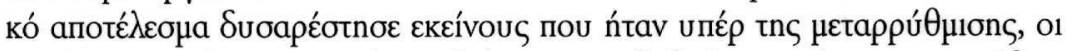

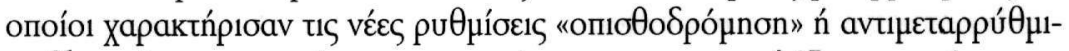

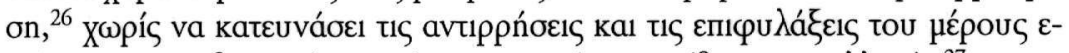

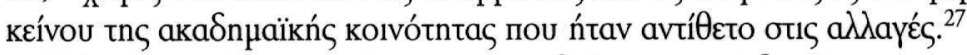

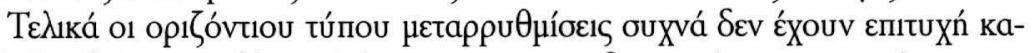

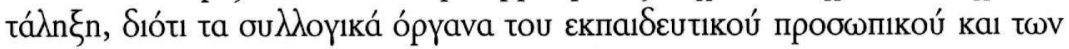

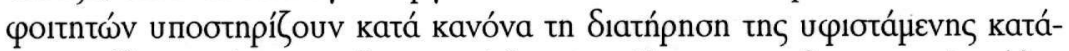

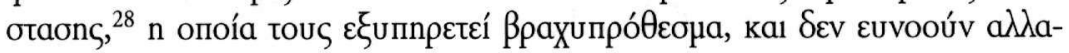

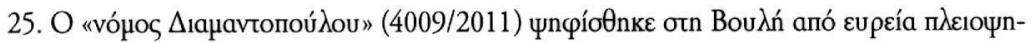

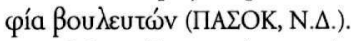

26. http://www.ethnos.gr/article.asp?catid=22768\&subid=2\&pubid=63691722 (про́оßaon 1.8.2012).

27. http://news.in.gr/greece/article/?aid=1231207465 (прóoßaon 1.8.2012).

28. K. Featherstone - D. Papadimitriou, The Limits of Europeanization. Reform Capacity and Policy Conflict in Greece, Palgrave Macmillan, Hampshire 2008, o. 203. 


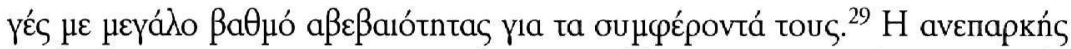

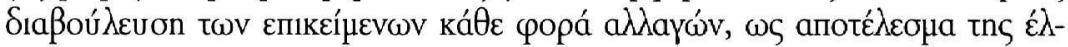
$\lambda \varepsilon ı \Psi n \varsigma$ ع

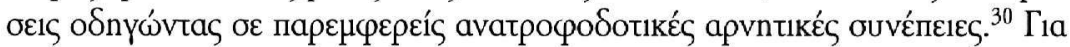

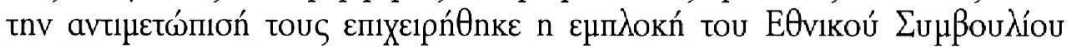

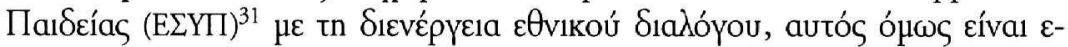

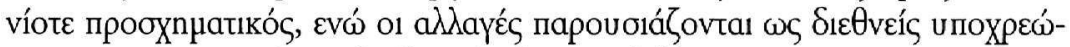

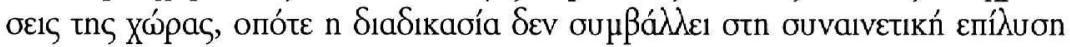

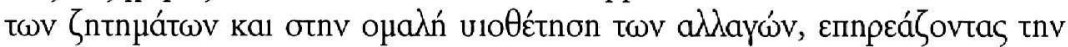

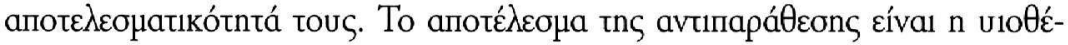

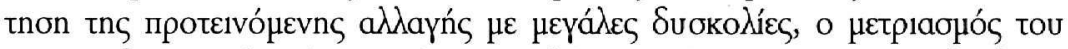

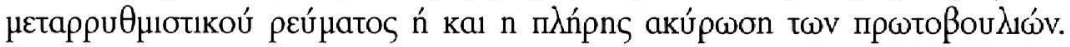

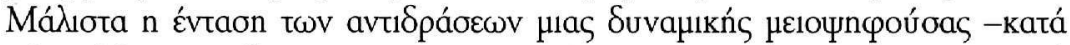

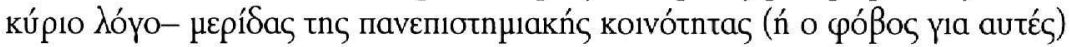

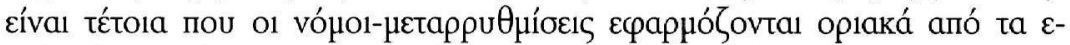

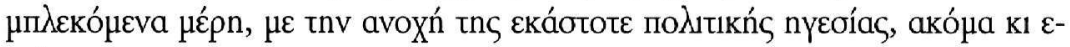

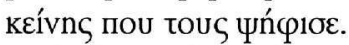

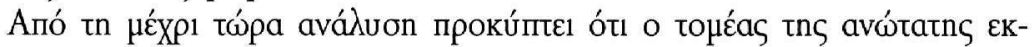

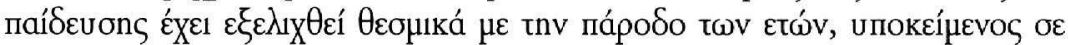

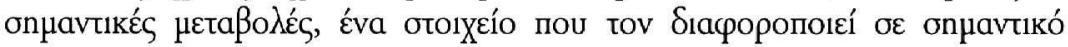

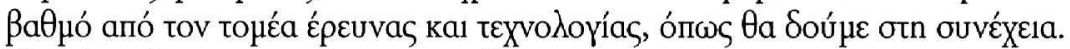

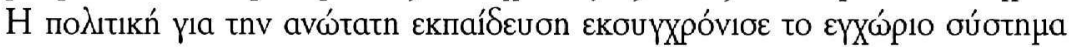

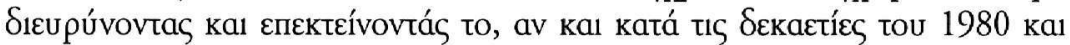

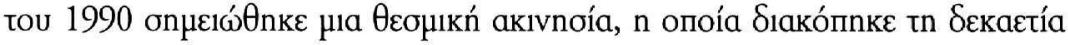

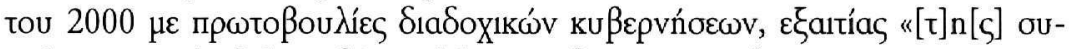

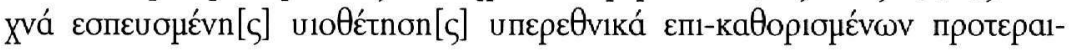

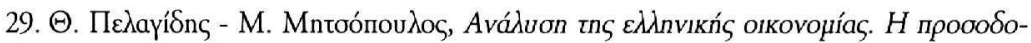

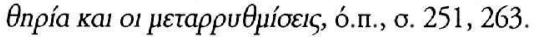

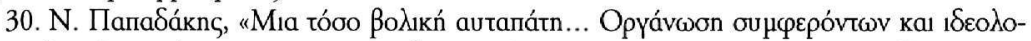

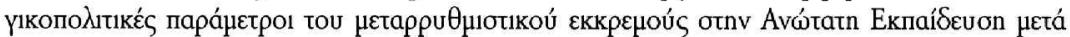

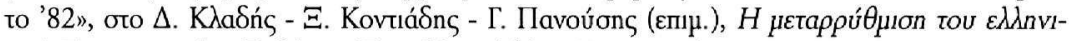

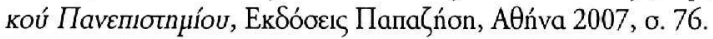

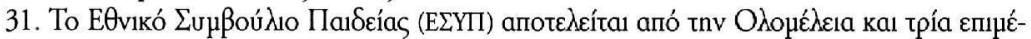

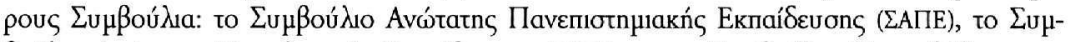

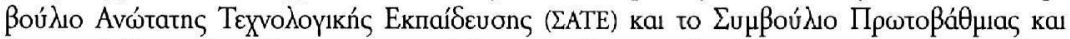

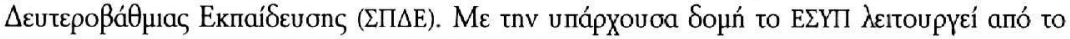
2003 (http://www.esyp.gr/index.php?option=com_content\&view=article\&kid=87:2012-02-0711-56-59\& catid=44:2011-09-15-11-30-50\&Itemid =54, прóoßaon 14.11.2012). 


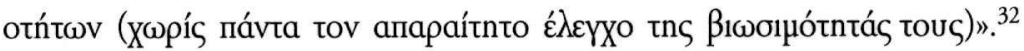

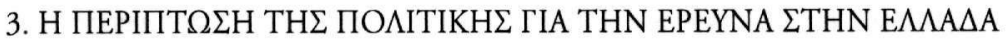

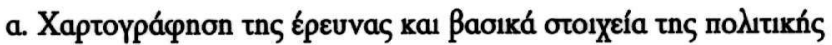

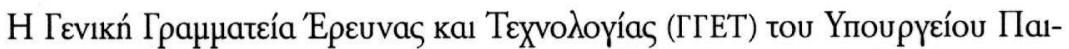

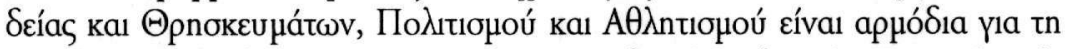

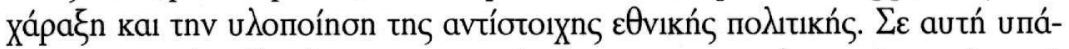

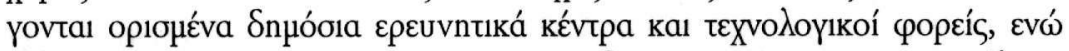

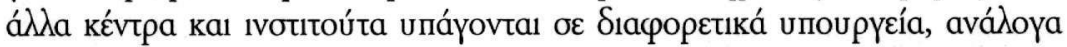

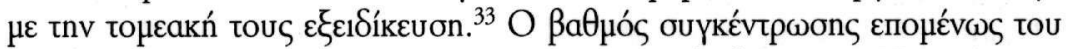

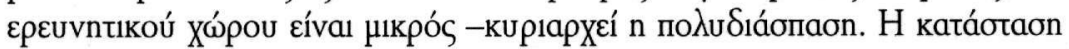

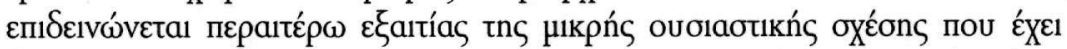

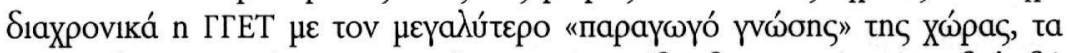

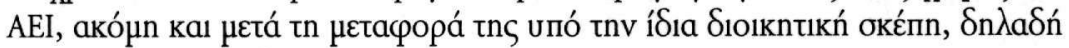
то Yпочрүвío Паıбвías.

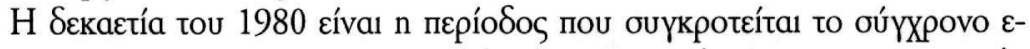

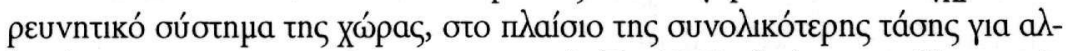

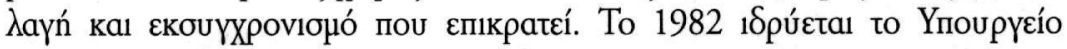

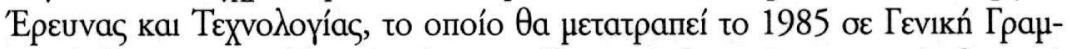

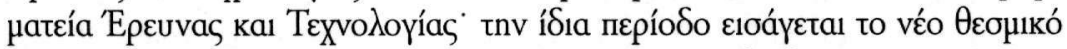

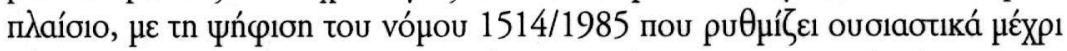

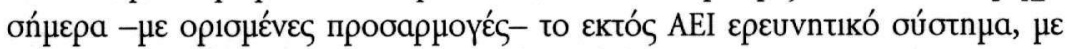

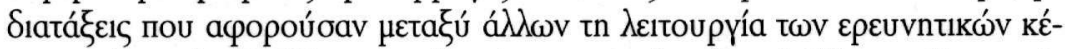

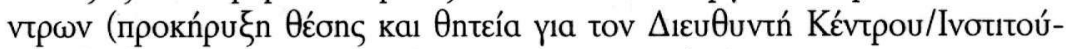

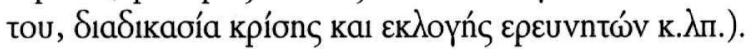

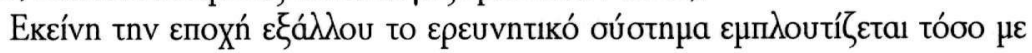

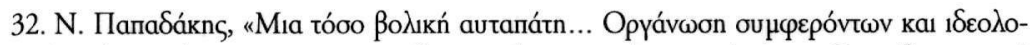

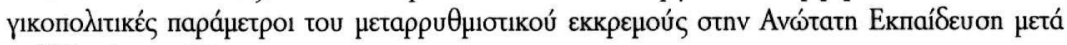
to '82", ó.п., б. 75.

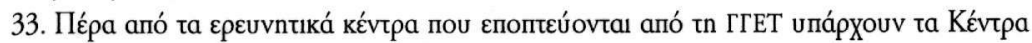

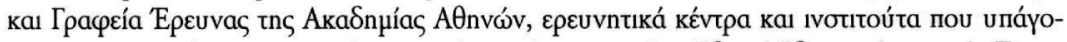

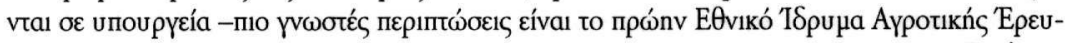

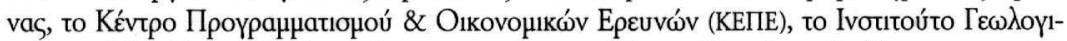

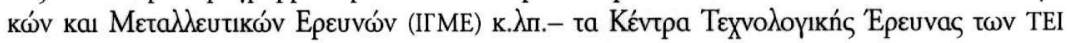

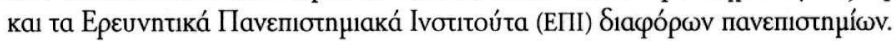




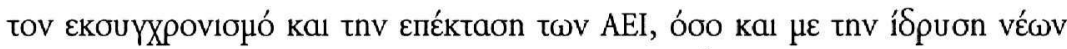

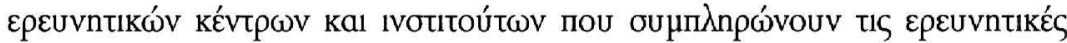

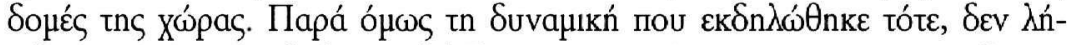
$\varphi \theta$ nkav unó

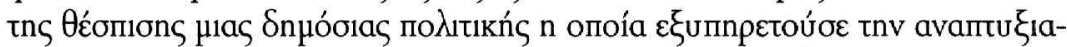

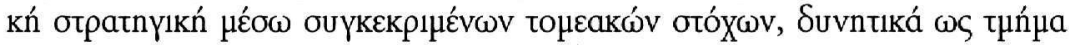

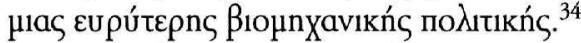

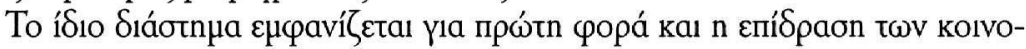

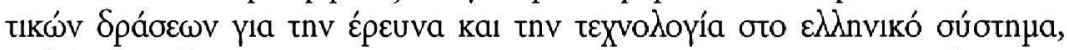

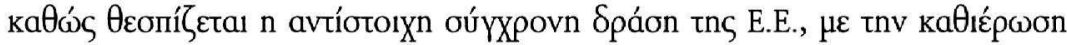

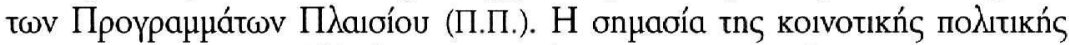

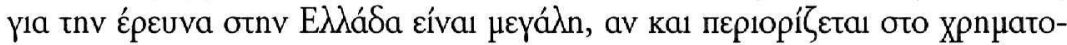

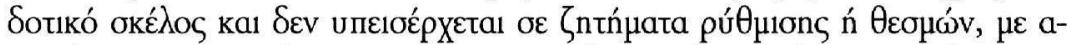

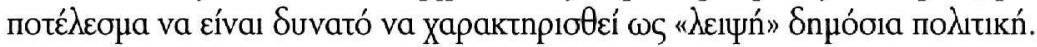

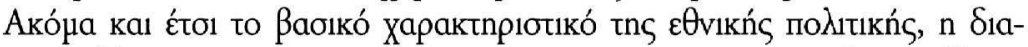

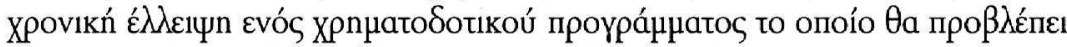

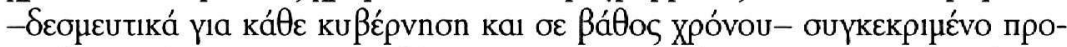

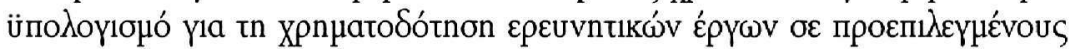

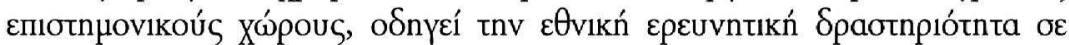

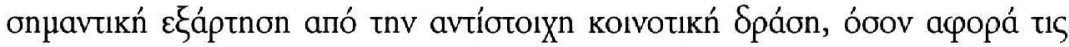

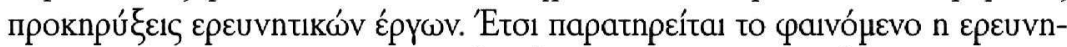

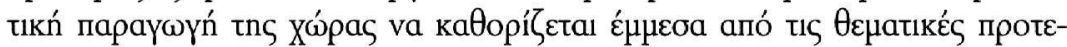

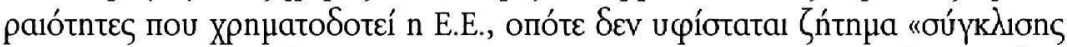

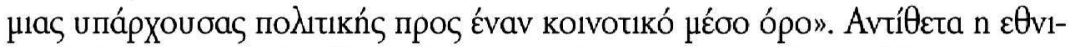

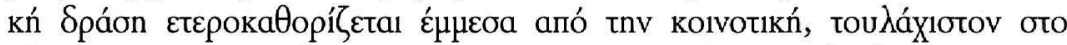

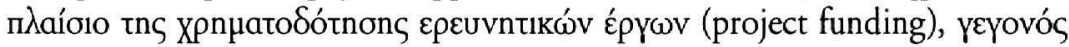

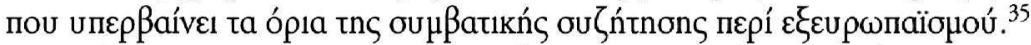

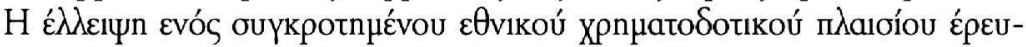

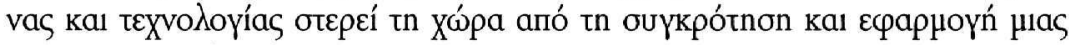

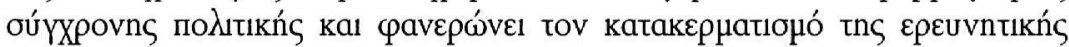

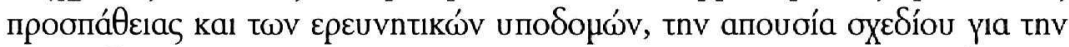

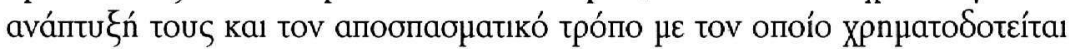

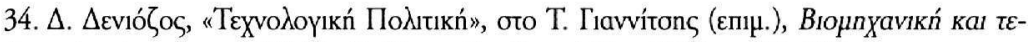

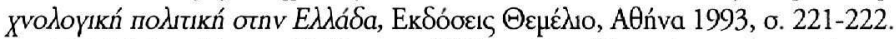

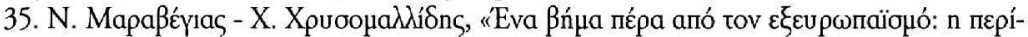

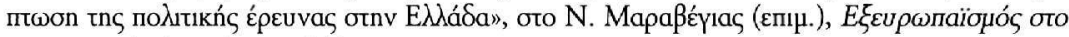
нвборєіако́ Хஸ́ро, ó.п., б. 342. 


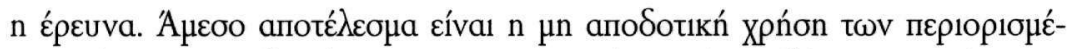

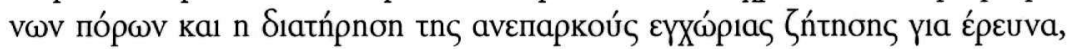

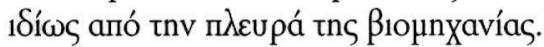

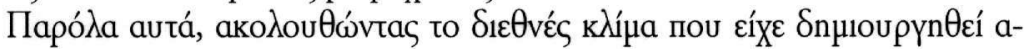

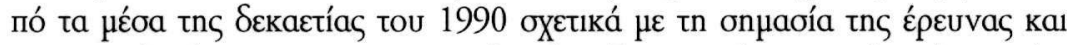

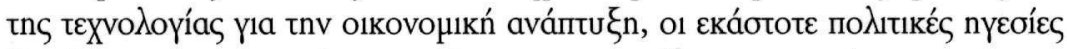

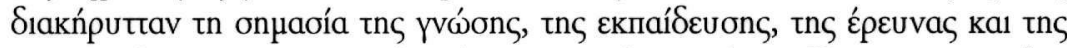

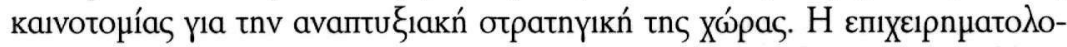

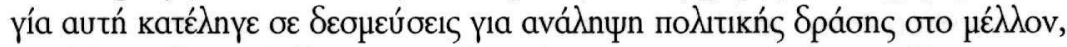

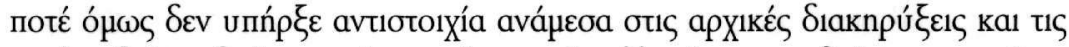

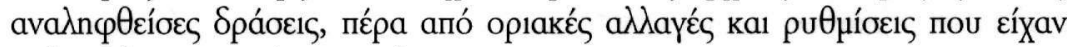
каӨара́ גeıtou үүıкó Характńра.

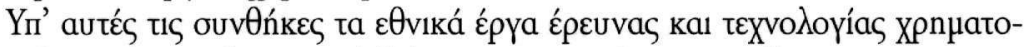

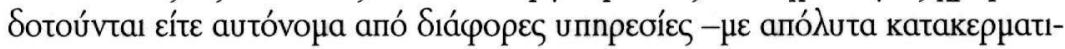

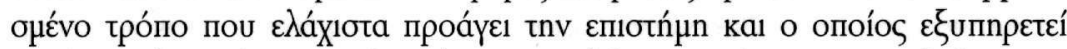

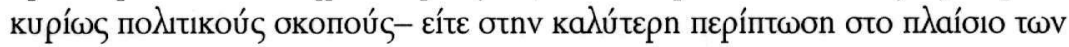

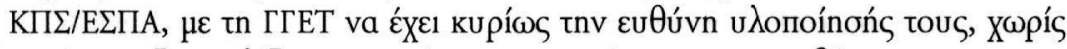

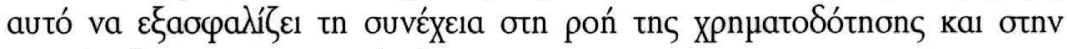

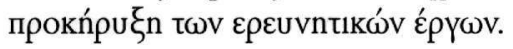

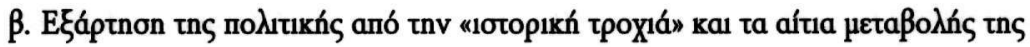

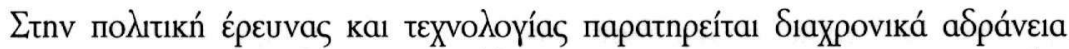

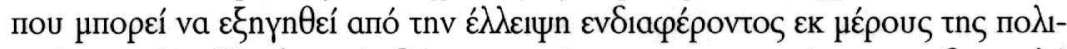

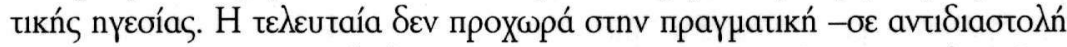

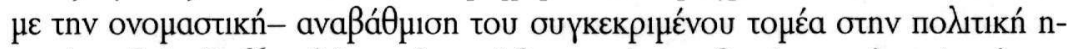

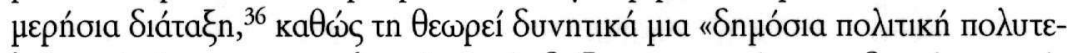

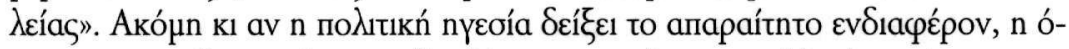

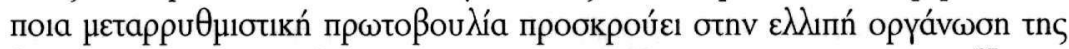

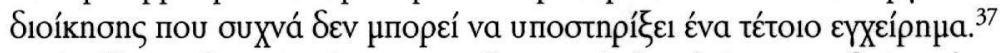

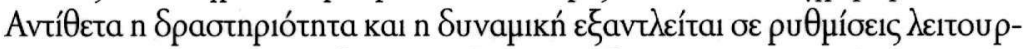

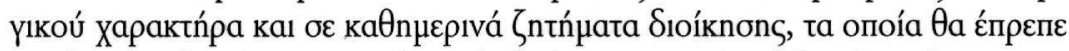

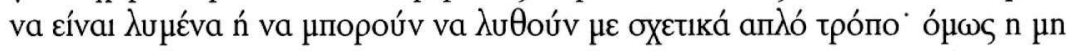

36. Erawatch, ERAWATCH Research Inventory Report for: GREECE, European Communities, Bрu $\zeta \dot{\varepsilon} \lambda \lambda \varepsilon \varepsilon$ 2009, о. 3.

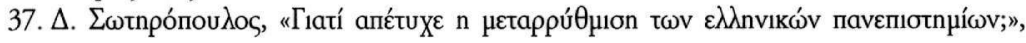
о́.п., о. 119. 


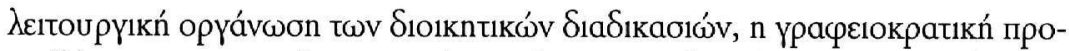

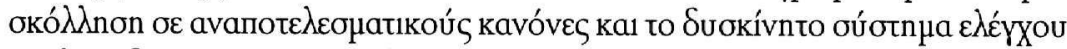

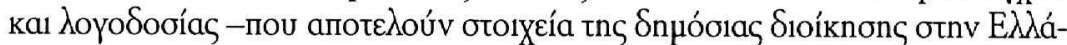

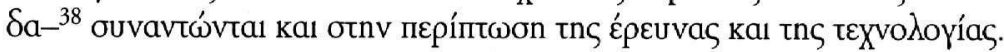

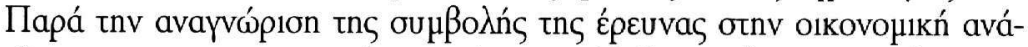

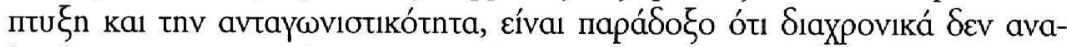

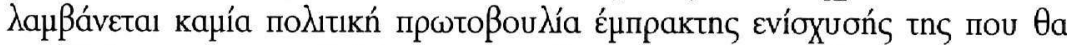

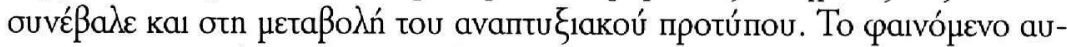

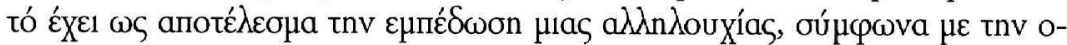

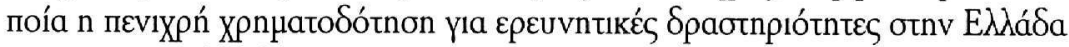

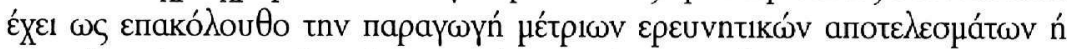

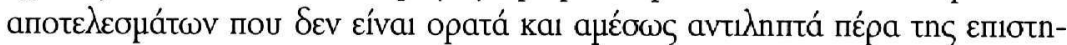

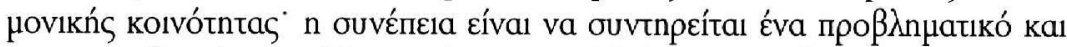

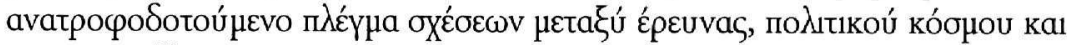
Kolv@víaç. ${ }^{39}$

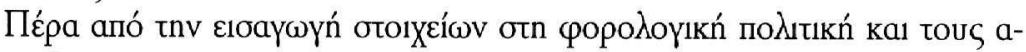

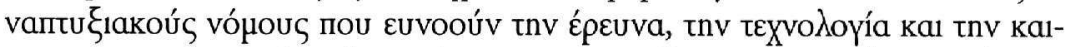

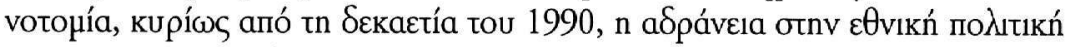

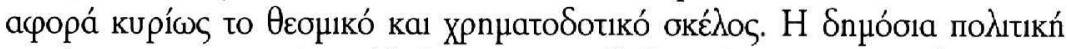

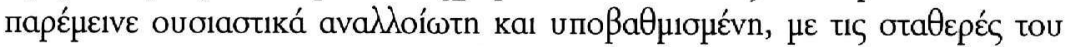

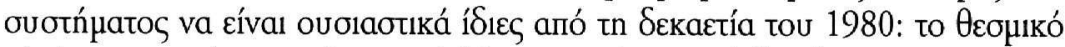

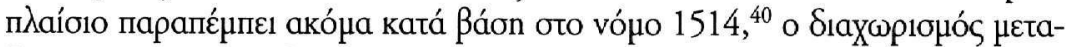

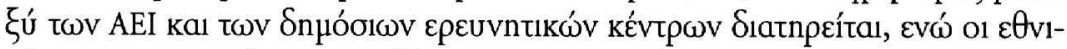

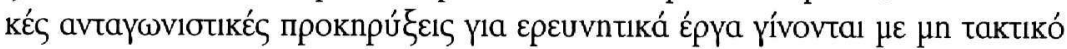

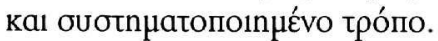

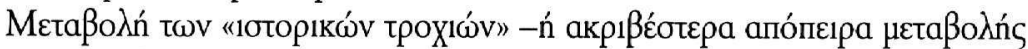

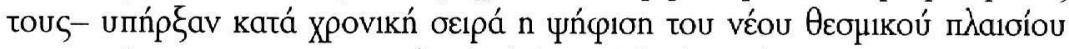

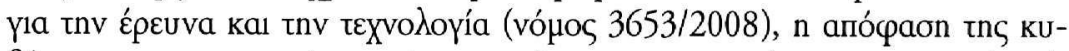

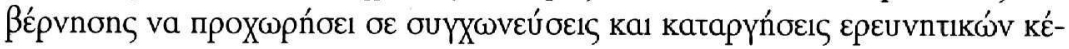

38. G. Doukidis - S. Smithson, Information Systems in the National Context. The Case of Greece, Avebury, Aldershot 1995, о. 226.

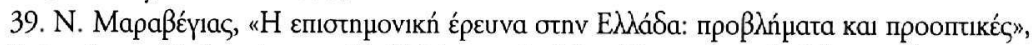

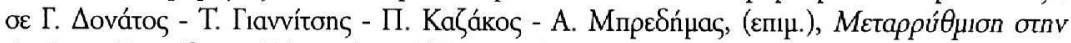

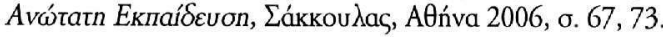

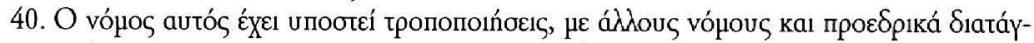

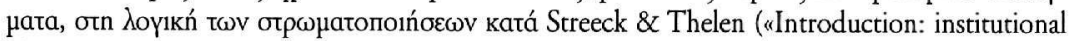

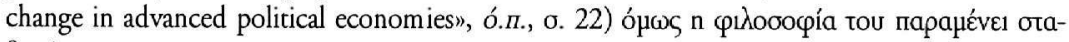
$\theta \varepsilon \rho n$. 


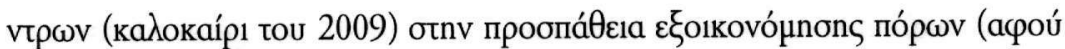

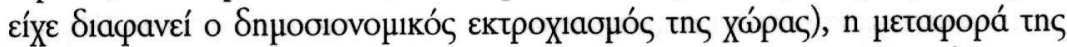

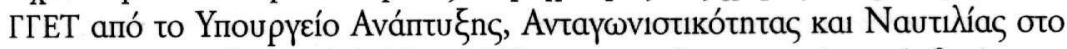

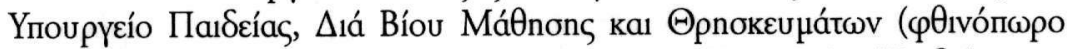
tou 2009), кaӨ

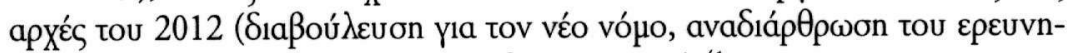

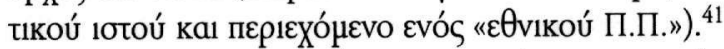

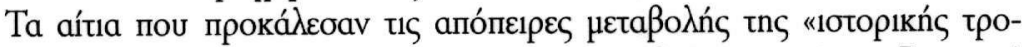

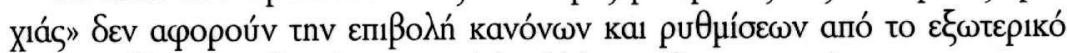

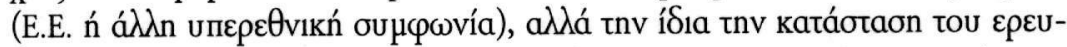

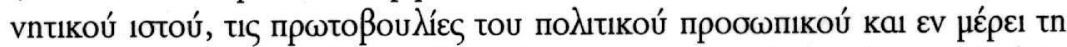

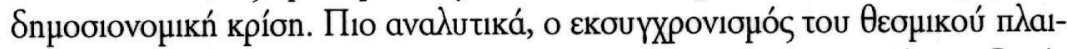

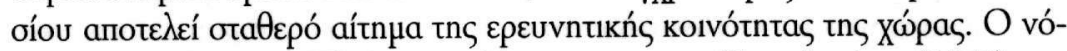

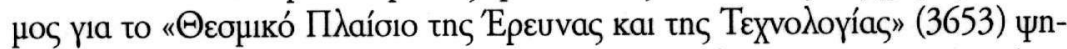

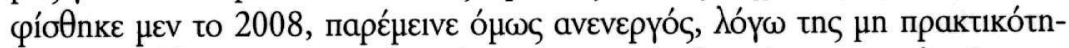

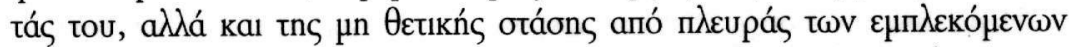

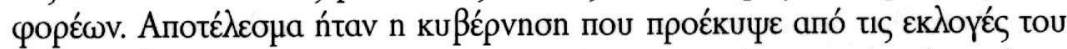

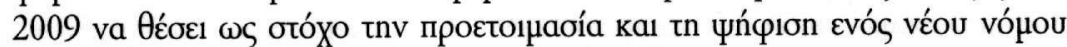

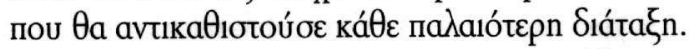

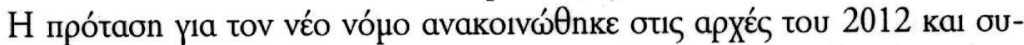

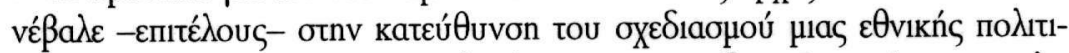

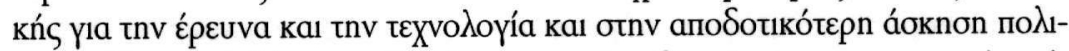

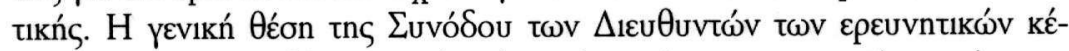

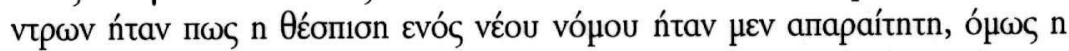

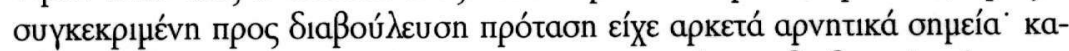

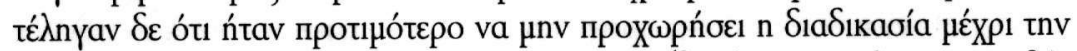

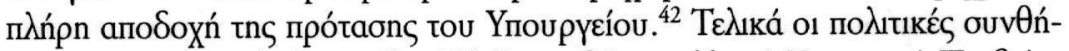

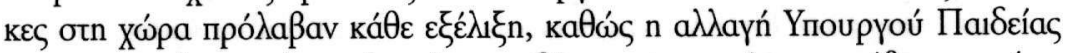

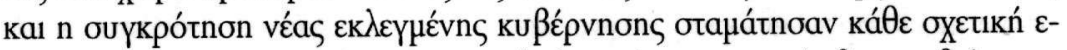

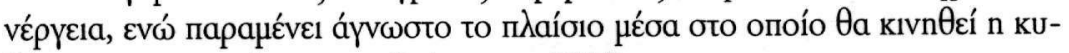

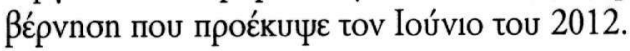

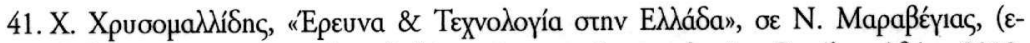

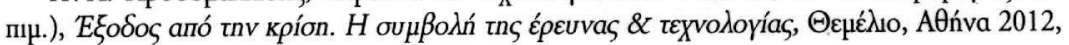
б. 129.

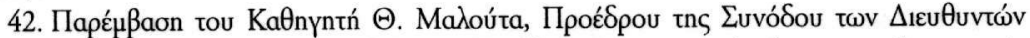

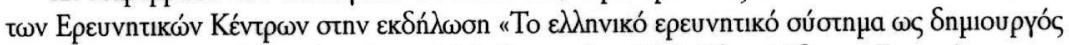

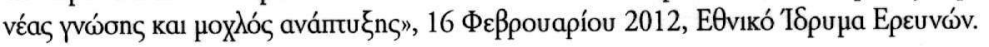




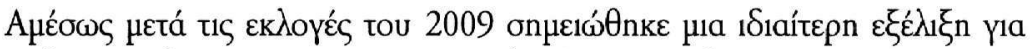

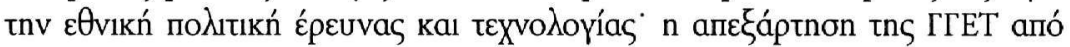

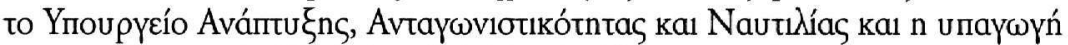
tn

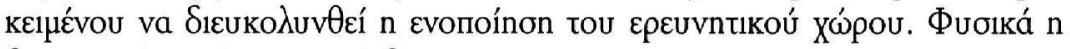

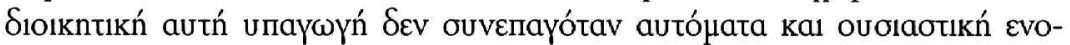

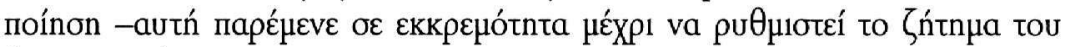

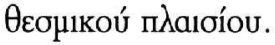

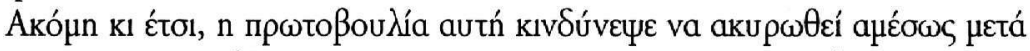

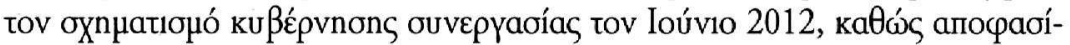

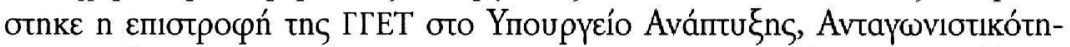

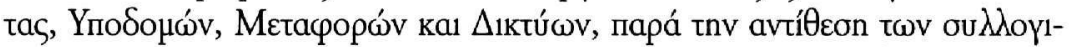

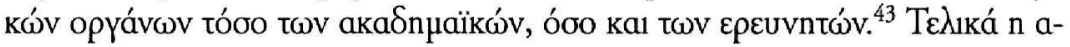

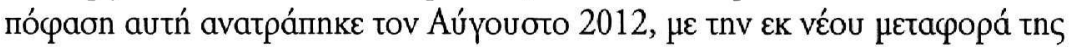

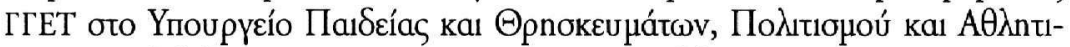

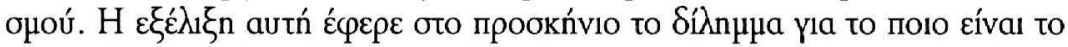

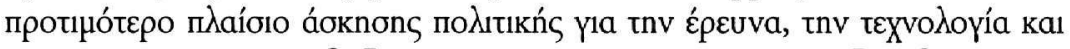

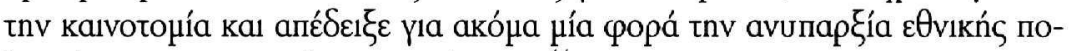

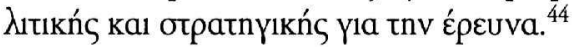

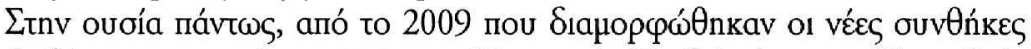

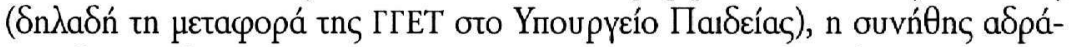

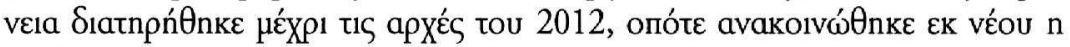

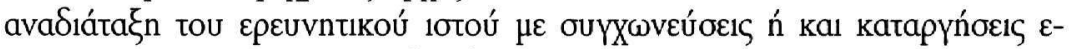

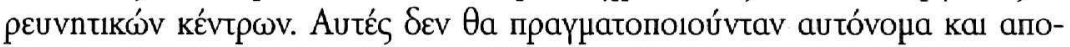

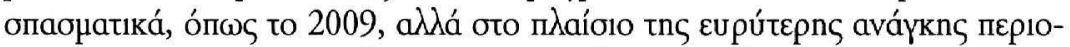

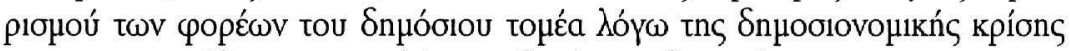

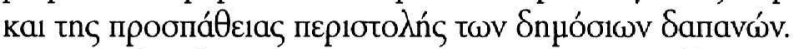

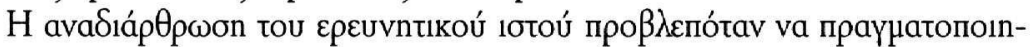

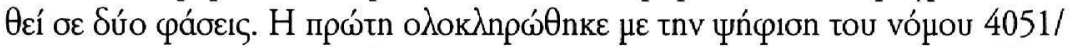

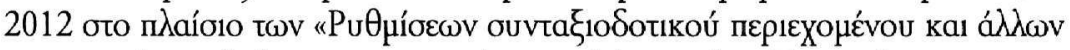

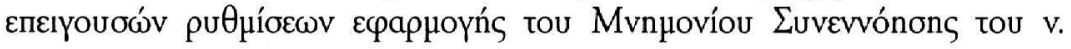

43. http://www.eee-researchers.gr/Anakoinoseis-EEE/POSDEP_OSEP-TEI_EEE_EpistoliProthupourgo_27-6-12.pdf (прóoßaon 06.08.2012).

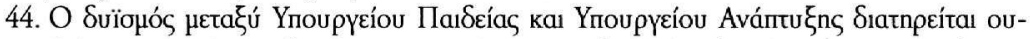

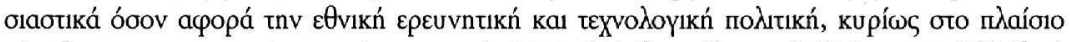

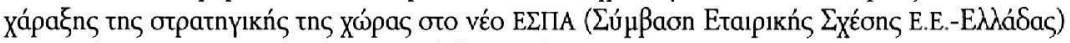

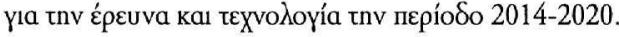




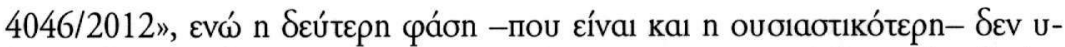

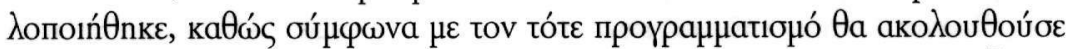

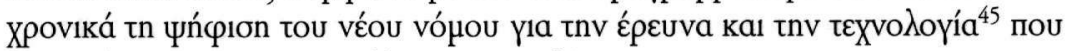

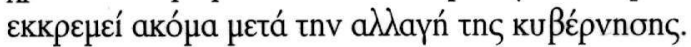

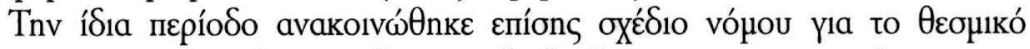

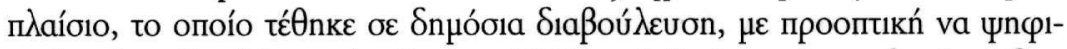

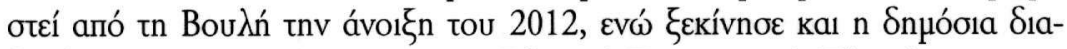

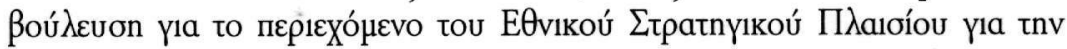

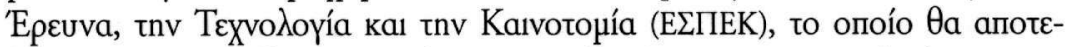

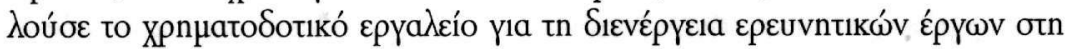

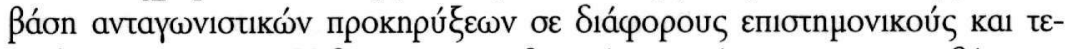

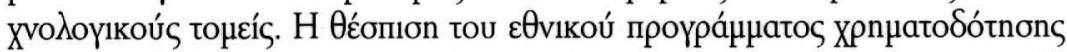

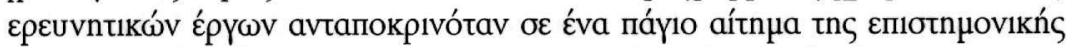

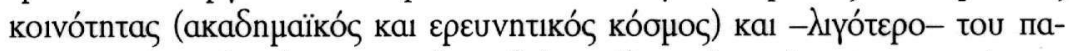

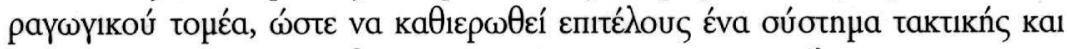

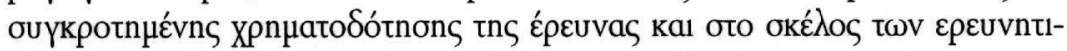

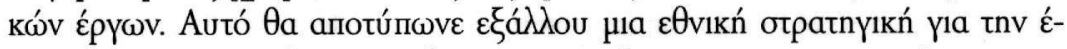

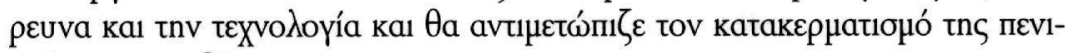
Xpńs Xpnuatođótnons.

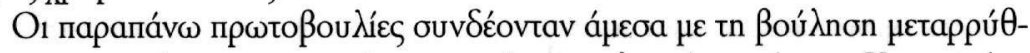

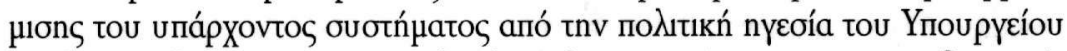

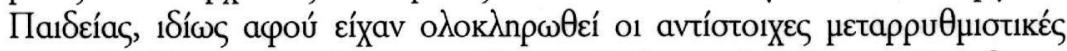

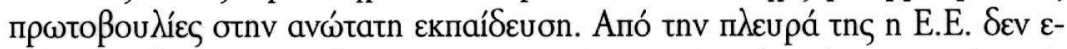

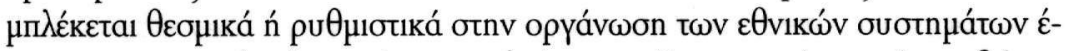

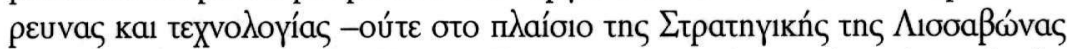

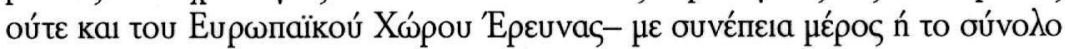

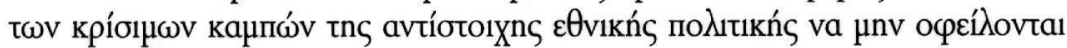

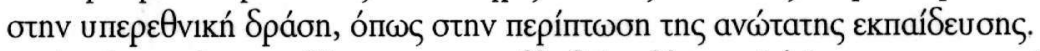

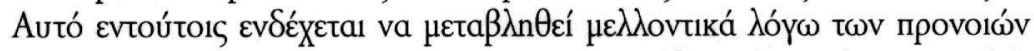

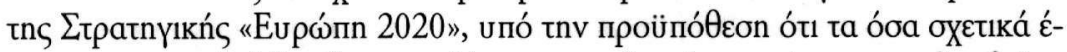

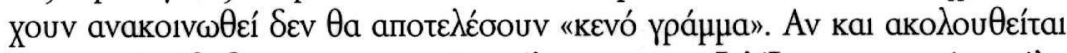

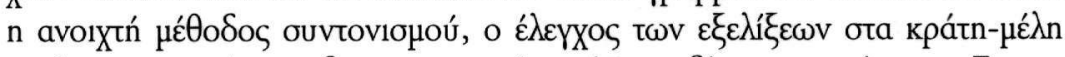

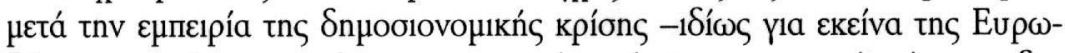

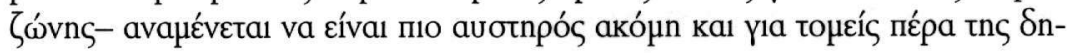

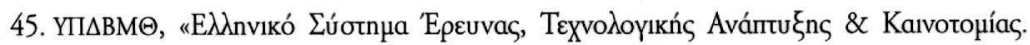

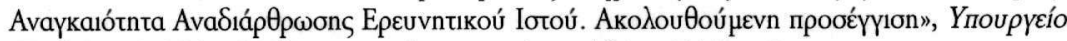

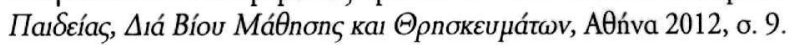




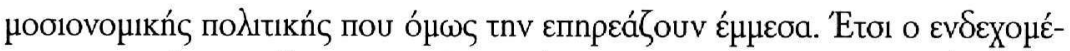

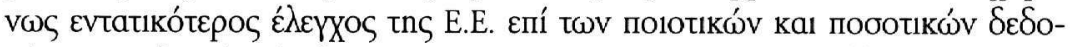

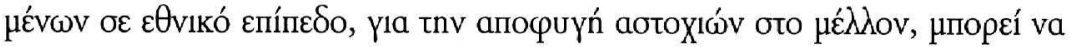

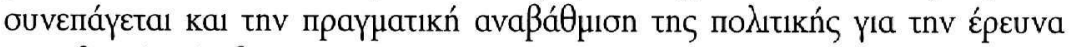

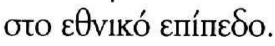

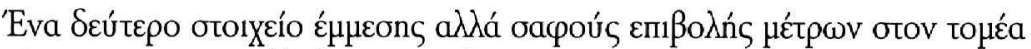

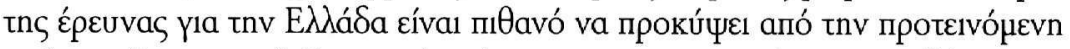

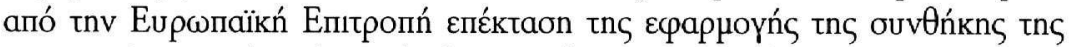

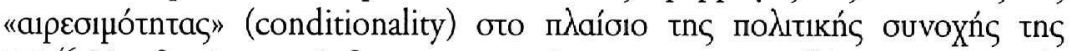

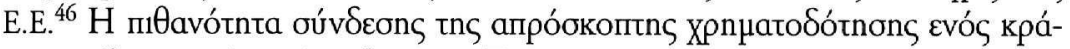

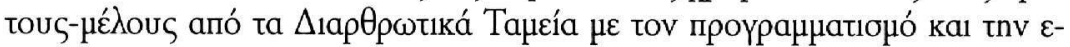

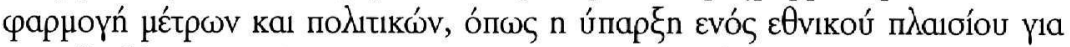

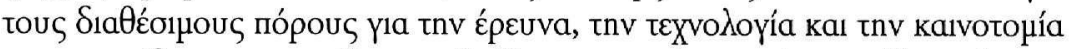

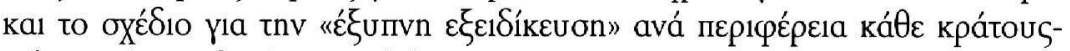

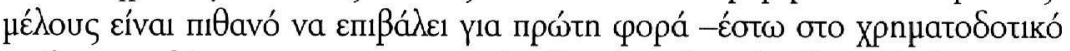

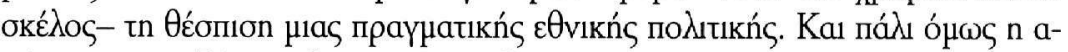

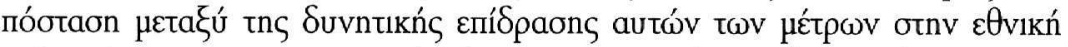

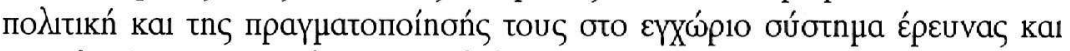

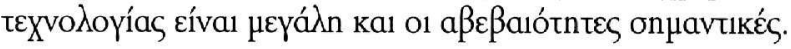

\section{4. ГYMПЕРАЕMATA}

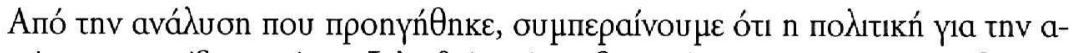

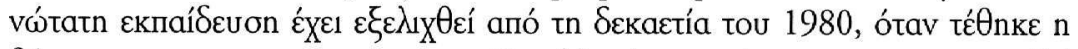

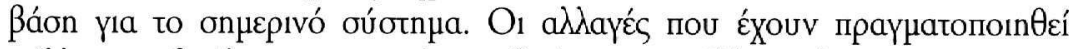

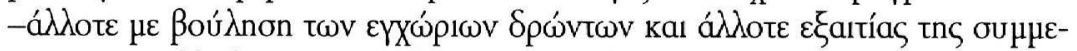
тoXń

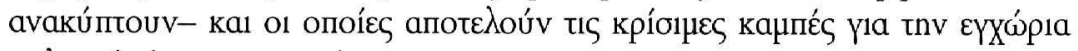

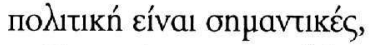

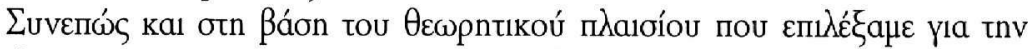

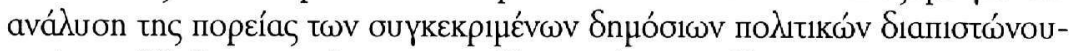

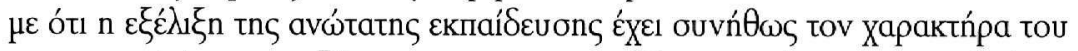

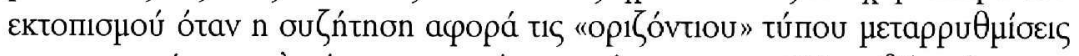

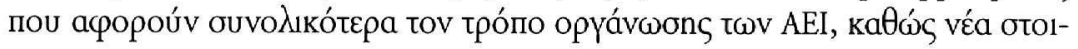

46. European Commission, Proposal for a Regulation of the European Parliament and of

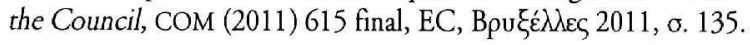




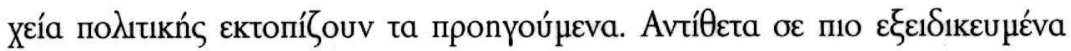

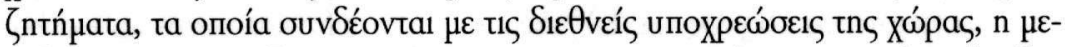

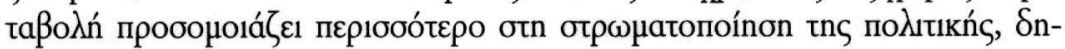

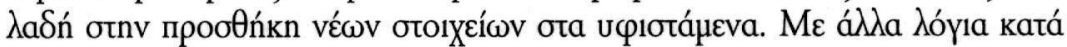

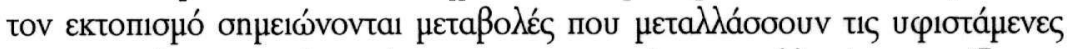

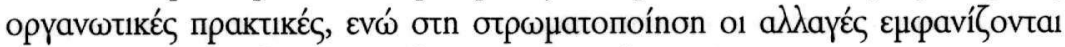

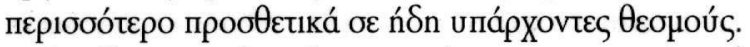

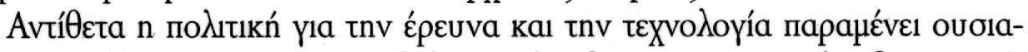

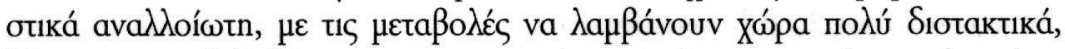

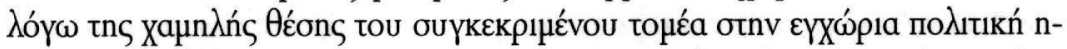

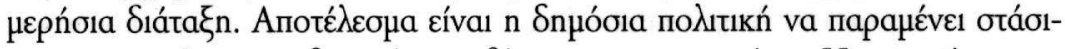

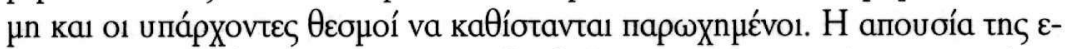

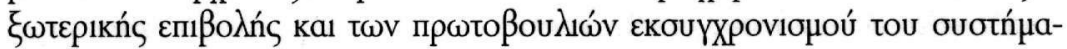

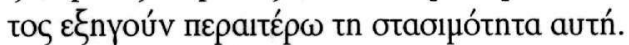

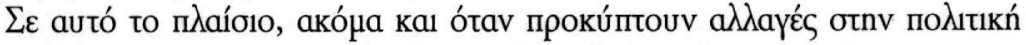

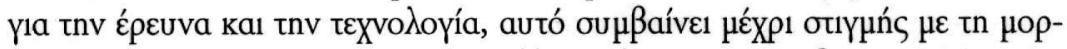

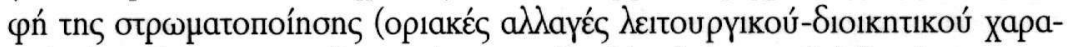

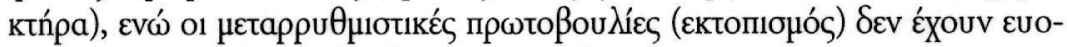

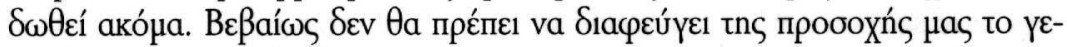

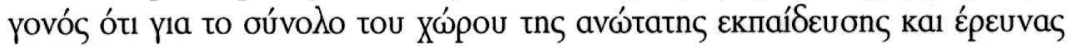
n anó

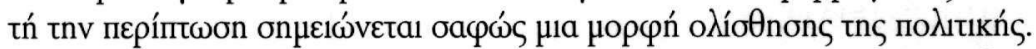

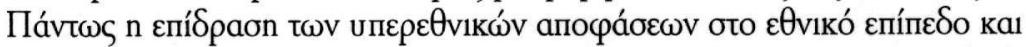

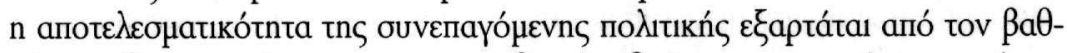

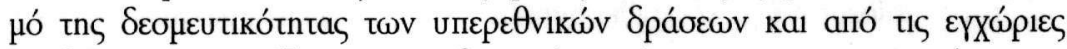

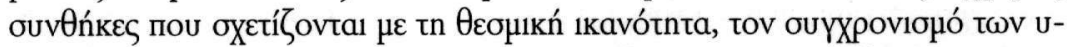

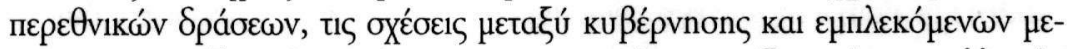

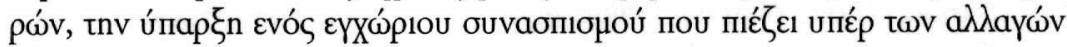

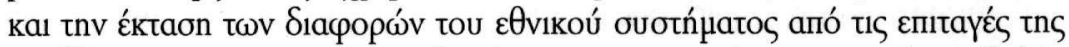

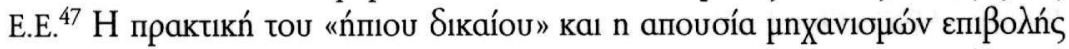

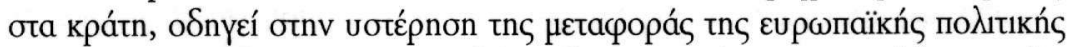

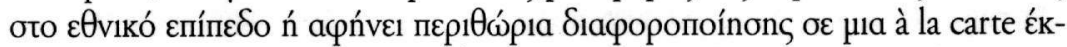

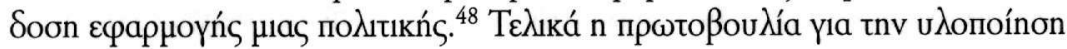

47. K. Featherstone - D. Papadimitriou, The Limits of Europeanization. Reform Capacity and Policy Conflict in Greece, ó.m., o. 189.

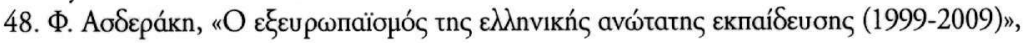
ó.I., б. 309-310. 


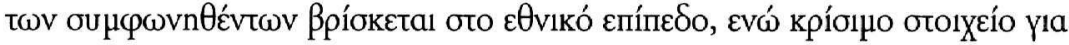

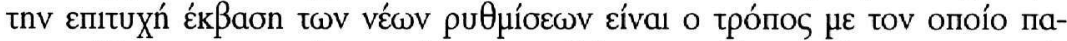

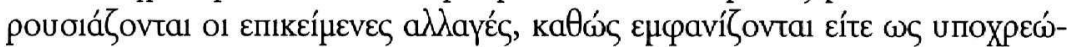

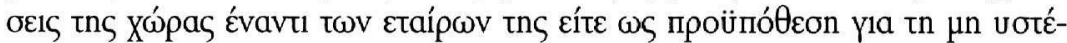

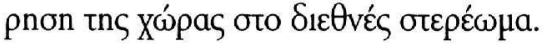

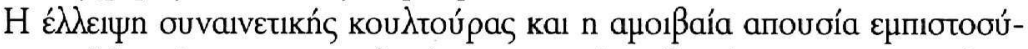

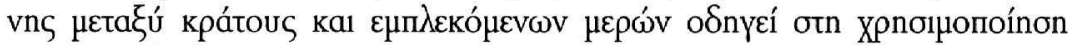

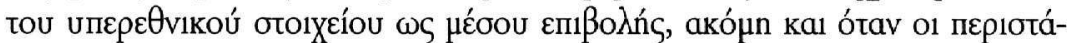

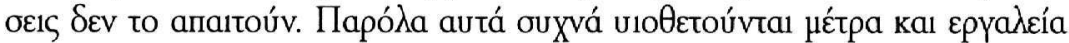

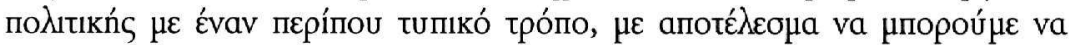

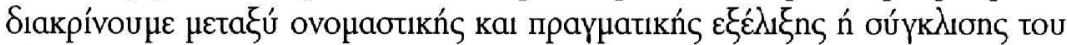

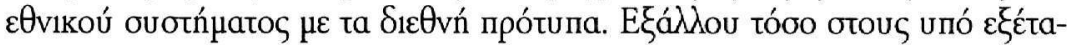

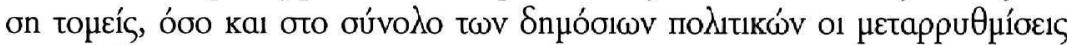

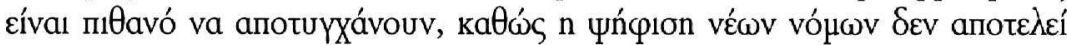

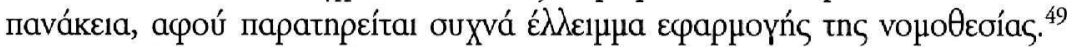

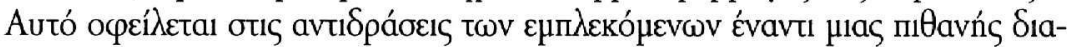

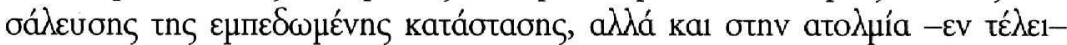

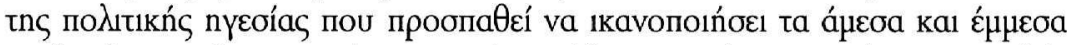

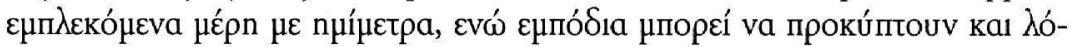

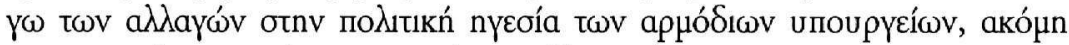

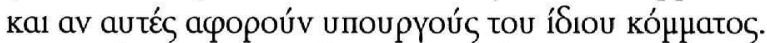

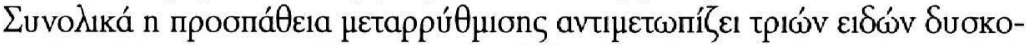

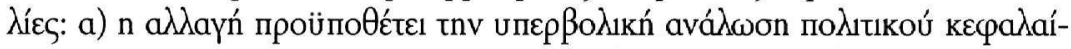

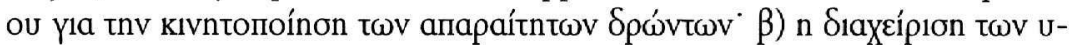

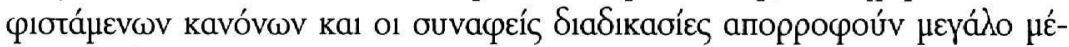

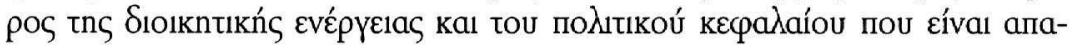

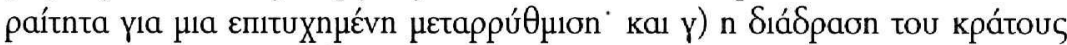

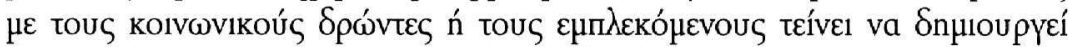

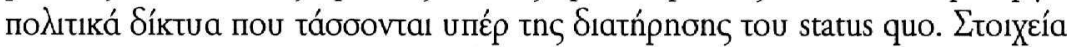

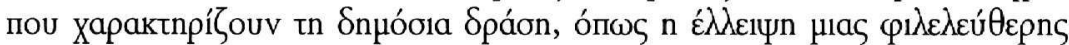

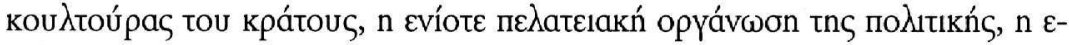

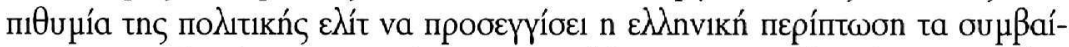

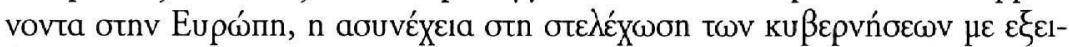

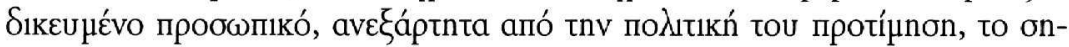

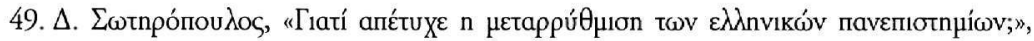
о́.п., б. 115. 


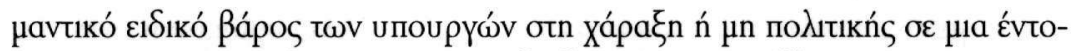

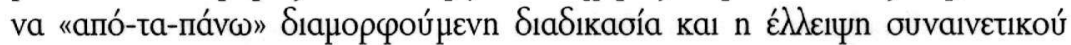

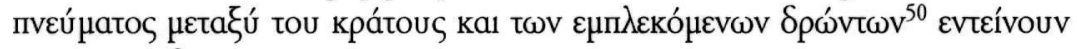

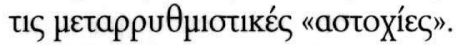

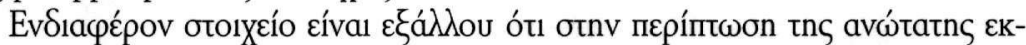

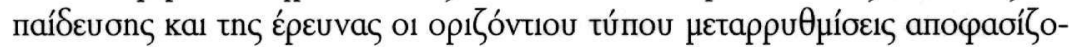

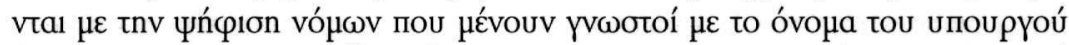

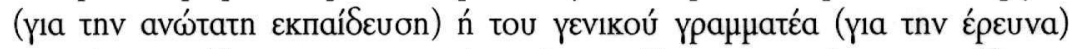

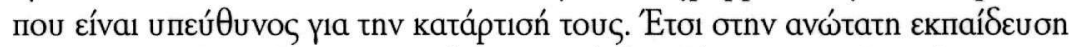

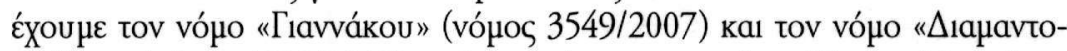

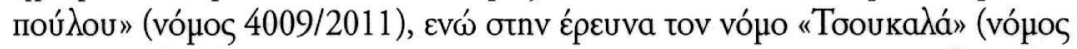

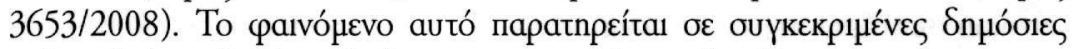

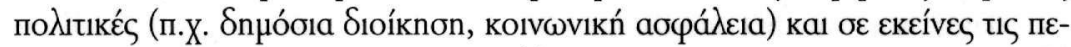

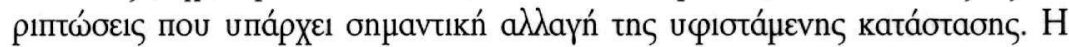

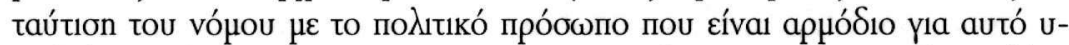

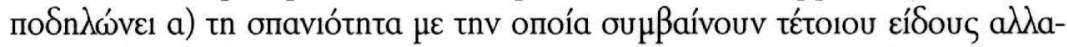

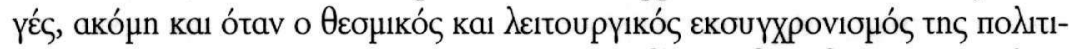

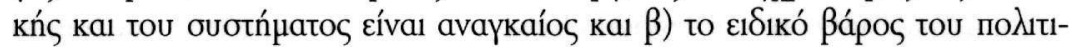

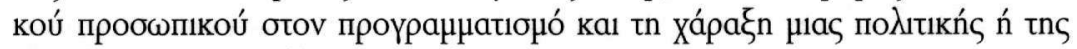

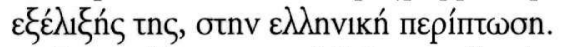

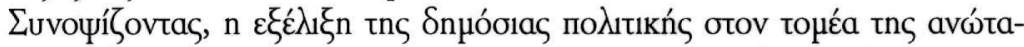

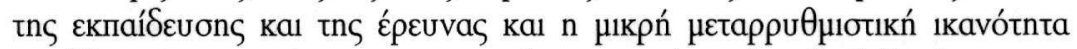

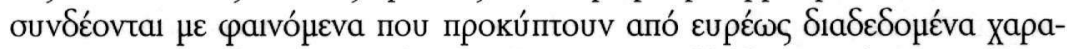

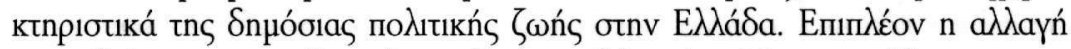

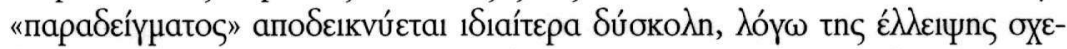

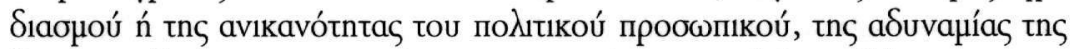

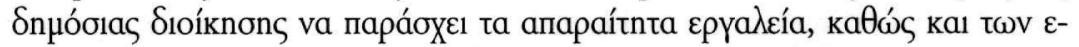

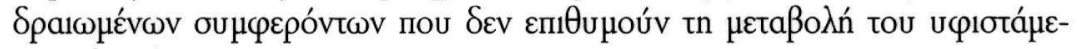
vou חגaıoíou.

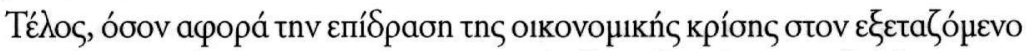

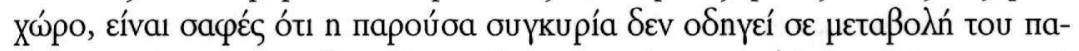

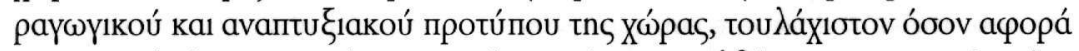

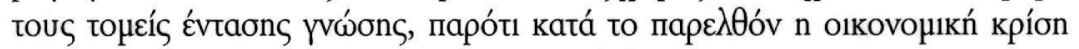

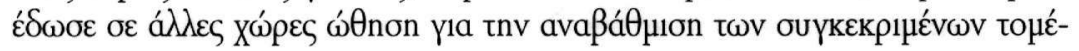

50. K. Featherstone - D. Papadimitriou, The Limits of Europeanization. Reform Capacity and Policy Conflict in Greece, ó.п., o. 41. 


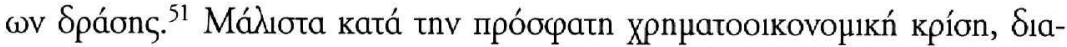

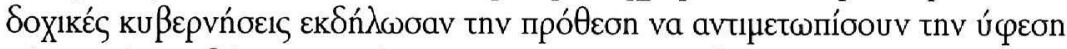

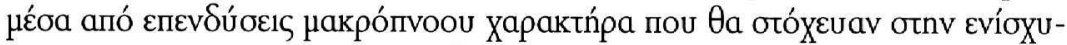

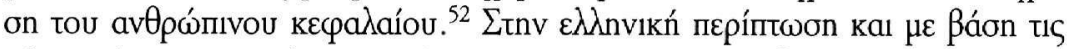

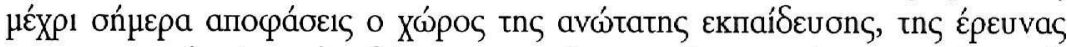

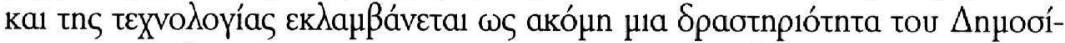

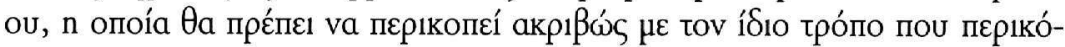

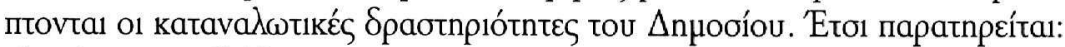

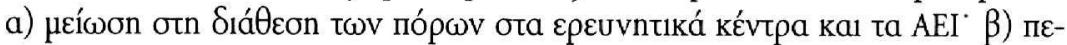

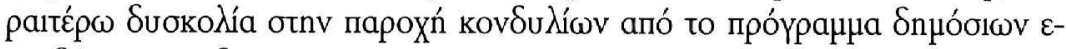

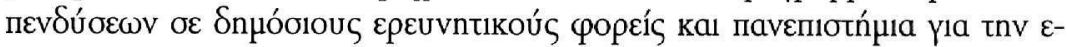

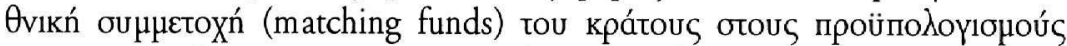

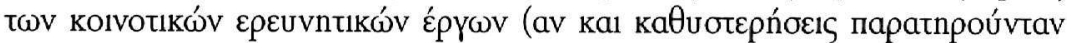

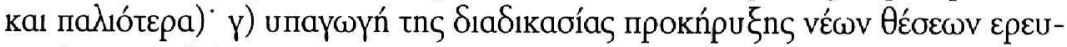

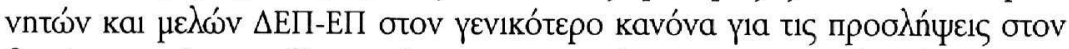

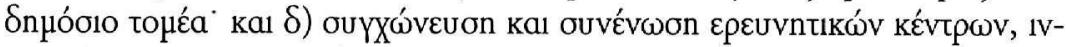

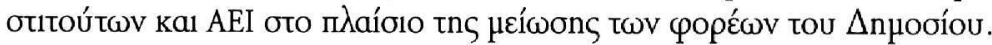

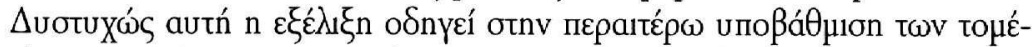

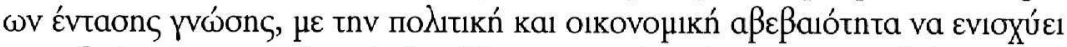

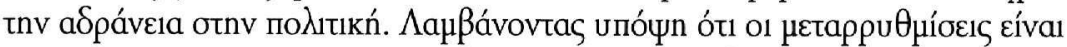

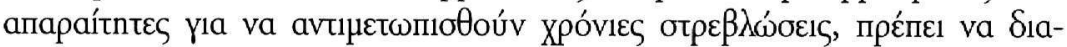

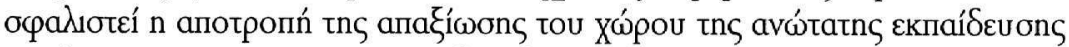

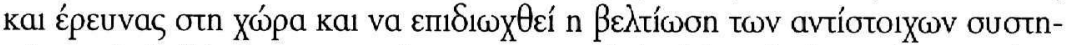

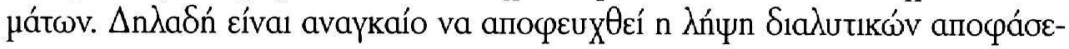

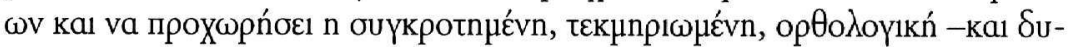

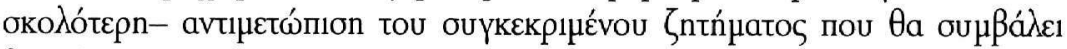

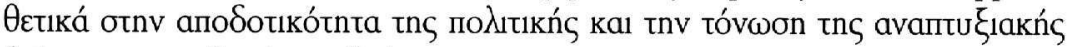

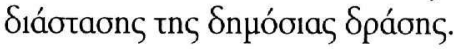

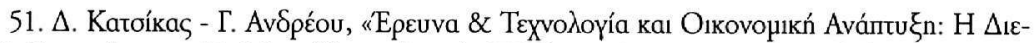

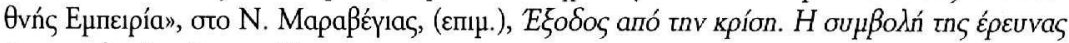
\& теXvodoyías, ó.п., о. 78.

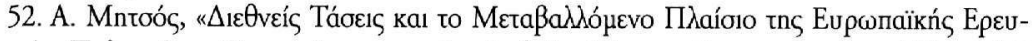

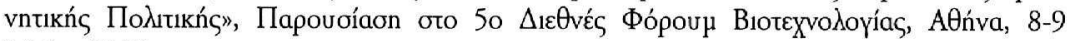
Maî̉ou 2009. 